\title{
Uniparental Markers of Contemporary Italian Population Reveals Details on Its Pre-Roman Heritage
}

\author{
Francesca Brisighelli ${ }^{1,2,39}$, Vanesa Álvarez-Iglesias ${ }^{1}$, Manuel Fondevila ${ }^{1}$, Alejandro Blanco-Verea ${ }^{1}$, \\ Ángel Carracedo ${ }^{1,4}$, Vincenzo L. Pascali ${ }^{2}$, Cristian Capelli ${ }^{3}$, Antonio Salas ${ }^{1 * 9}$
}

1 Unidade de Xenética, Facultade de Medicina, Instituto de Medicina Legal, Universidade de Santiago de Compostela, Galicia, Spain, 2 Forensic Genetics Laboratory, Institute of Legal Medicine, Università Cattolica del Sacro Cuore, Rome, Italy, 3 Department of Zoology, University of Oxford, Oxford, United Kingdom, 4 Fundación Pública Galega de Medicina Xenómica (FPGMX-SERGAS), CIBER enfermedades raras, Santiago de Compostela, Galicia, Spain

\begin{abstract}
Background: According to archaeological records and historical documentation, Italy has been a melting point for populations of different geographical and ethnic matrices. Although Italy has been a favorite subject for numerous population genetic studies, genetic patterns have never been analyzed comprehensively, including uniparental and autosomal markers throughout the country.

Methods/Principal Findings: A total of 583 individuals were sampled from across the Italian Peninsula, from ten distant (if homogeneous by language) ethnic communities - and from two linguistic isolates (Ladins, Grecani Salentini). All samples were first typed for the mitochondrial DNA (mtDNA) control region and selected coding region SNPs (mtSNPs). This data was pooled for analysis with 3,778 mtDNA control-region profiles collected from the literature. Secondly, a set of Ychromosome SNPs and STRs were also analyzed in 479 individuals together with a panel of autosomal ancestry informative markers (AIMs) from 441 samples. The resulting genetic record reveals clines of genetic frequencies laid according to the latitude slant along continental Italy - probably generated by demographical events dating back to the Neolithic. The Ladins showed distinctive, if more recent structure. The Neolithic contribution was estimated for the Y-chromosome as $14.5 \%$ and for mtDNA as 10.5\%. Y-chromosome data showed larger differentiation between North, Center and South than mtDNA. AIMs detected a minor sub-Saharan component; this is however higher than for other European non-Mediterranean populations. The same signal of sub-Saharan heritage was also evident in uniparental markers.
\end{abstract}

Conclusions/Significance: Italy shows patterns of molecular variation mirroring other European countries, although some heterogeneity exists based on different analysis and molecular markers. From North to South, Italy shows clinal patterns that were most likely modulated during Neolithic times.

Citation: Brisighelli F, Álvarez-Iglesias V, Fondevila M, Blanco-Verea A, Carracedo Á, et al. (2012) Uniparental Markers of Contemporary Italian Population Reveals Details on Its Pre-Roman Heritage. PLoS ONE 7(12): e50794. doi:10.1371/journal.pone.0050794

Editor: David Caramelli, University of Florence, Italy

Received June 15, 2012; Accepted October 24, 2012; Published December 10, 2012

Copyright: (ㄷ 2012 Brisighelli et al. This is an open-access article distributed under the terms of the Creative Commons Attribution License, which permits unrestricted use, distribution, and reproduction in any medium, provided the original author and source are credited.

Funding: The research leading to these results has received funding from the People Programme (Marie Curie Actions) of the European Union's Seventh Framework Programme FP7/2007-2013/under REA grant agreement number 290344, and the Ministerio de Ciencia e Innovación (SAF2008-02971 and SAF201126983)(AS). CC and FB were partially funded by the British Academy for the project "The Greeks in the West: the genetic legacy of the colonisation in South Italy and Sicily". The funders had no role in study design, data collection and analysis, decision to publish, or preparation of the manuscript.

Competing Interests: The authors have declared that no competing interests exist.

*E-mail: antonio.salas@usc.es

9 These authors contributed equally to this work.

\section{Introduction}

Italy has historically been a convenient destination for human populations migrating from Africa, the Middle East and European locations, in part due to the geomorphological characteristics of the Italian Peninsula [1]. These groups settled preferentially on the islands and coastal territories [1] 500,000 years ago (ya), that is, along the Lower Paleolithic, the longest period of human prehistory, which was dominated by the notable diffusion of tools made from flaked stone [2]. Although rich in tools and animal bones, only some of these sites have provided a small quantity of human skeletal remains resembling those from the more recent sites of the Middle Paleolithic, dating to the Riss-Würm interglacial period and part of the succeeding Würm glaciation (circa 120,000 to 36,000 ya). These bones belong to a species named Homo sapiens neanderthalensis. [2] In this long Paleolithic period, navigation across the Mediterranean was probably rare and some present-day islands were accessible across land bridges later covered by the rising sea [3]. During the Upper Paleolithic, from 36,000 to 10,000 ya, the icecap expansion of the Late Glacial Maximum (LGM) pushed southward groups of hunters living in Central European areas [1], and the Neanderthals gave way to the present species of man Homo sapiens sapiens during the final phases of the Würm glaciation. The numerous traces from this period are particularly rich in burials, animal bones and tools, the latter having been worked with increased precision [2]. In the few thousand years of the following Mesolithic period (circa 10,000 to 6,000 ya) the climate continued to grow milder and sites from this period have been found throughout the entire Italian peninsula, being along the coasts in the plains and on the mountains. With 
the Neolithic period, from circa $6,000 \mathrm{BC}$ to $2,800 \mathrm{BC}$, the traditional hunting and gathering economy was replaced by the introduction of agriculture, stock rearing, weaving and pottery. This new cultural influence came particularly from the Eastern Mediterranean and the Near East. Using the pottery production above all, it has been possible to reconstruct fairly accurately the various phases of this complex period [2]. During the Copper, Bronze and Iron ages, numerous population movements occurred between the Mediterranean basin and the Middle East [4]. Exchange of metals would determine the transformation of the first social organizations in ancient civilizations [4]. Sardinia, Sicily and Tuscany were among the first Italian territories to be occupied by humans due to their strategic location and the presence in their territories of important metal resources [5].

Different cultures, recognized on the basis of different archeological findings, settlements and burial traditions, arose in the period between the Mesolithic and Iron Age. Before the Roman conquest, ancient Italy was characterized only by the presence of Indo-European populations [6] living in the Italian Peninsula since the second millennium $\mathrm{BC}$, corresponding to the period between the Iron Age and Romanization [2]. During all this period there were also increasing contacts with the Phoenician and Greek colonists: the former being largely present on the coasts of Sardinia and western Sicily and the latter in Southern Italy. These colonies had a considerable influence on the development of local cultures (from the Picenian to Campano-Samnite and the Apulian to Bruttio-Lucanian) [5].

The record of all the populations that inhabited the Italian territory during (pre)-history is incomplete; many records were of uncertain location and/or ambiguous denomination [6]. At the beginning of the first millennium $\mathrm{BC}$ the following native tribes could be distinguished on the Italian territory: the Ligures, on the coast that bears their name, in the northern Apennine valleys, part of the pre-alpine valleys and the western Po Valley; the Sicani, in the interior of Sicily; and the Itali, in present-day Calabria (from whom comes the name 'Italy', which was to be extended to all the territory of the peninsula). Besides the already mentioned Terramare tribe, on the southern edge of the Po Valley, and the Villanovans, probably from Eastern Europe who settled throughout Central Italy, there were also the Umbrians to the east of the upper basin of the Tiber. The Veneti, who occupied the territory that still bears their name, originally came from Illyria as did the Messapii (now modern Salento or South Apulia) and Iapyges, who settled in present-day Puglia (Apulia) [5]. Many other populations of Central-Southern Italy were created by the mixing of local and foreign elements dating back to the previous millennium; it is the case of the Sabines and Latini who settled in Lazio together with Falisci, Aequi, Volsci, Hernici and Ausones. The interior of Abruzzo was dominated by the Vestini, Paeligni and Marsi, while the central Adriatic coast was populated by Picentes, Marrucini and Frentani. The Apennine area of Molise and Basilicata was peopled by the Samnites and Lucanians. In Calabria and Sicily there were also the Bruttii and Siculi.

The Phoenician colonization of the coasts of the Western Mediterranean were mainly limited in Italy to Sardinia and western Sicily and preceded that of the Greeks. It was followed by Punic settlements (Trapani, Palermo, Cagliari) linked to the ancient Phoenician colony of Carthage.

At the time of the Roman Empire, at least two non-IndoEuropean populations still inhabited Italy, namely, the Ligures, in the northwestern area, and the Etruscans with settlements located in areas far from the Etruria (Tuscany and High Latium), such as the Po Plain and the coast of Campania. At the same time, Sardinia experienced the flourishing of a non-Indo-European Nuragic civilization and, then, the Phoenician colonization.

Genetics alone cannot disentangle the extremely complex demography of Italy through history. Some demographic movements have however left signals on uniparental and nuclear markers. Most of the genetic studies targeted local, e.g. [7], or regional, e.g. [8-11], Italian populations.

For the Y-chromosome, some attempts have been undertaken to analyze Italian variation to a more general scale [12-14]. Many studies have analyzed specific haplogroups in the Y-chromosomes, e.g. $[15,16]$, or the mtDNA, e.g. $[8,9]$. In general, the different studies indicate that the genetic structure of the present Italian population seems to reflect, at least in part, the ethnic stratification of pre-Roman times [14]. Studies carried out in the past appear to show a major North-South cline consistent with archaeological estimates of two distinct processes: the first colonization of the area during the Paleolithic period and the subsequent Neolithic expansion from the Middle East after the last glacial [14]. There is some correspondence between patterns of variation at the Ychromosome and geography. Thus, northern Italy shows similar frequencies as the haplogroups of Central Europe, with prevalence of the western R1-M173 haplogroup compare to the eastern IM170. In the North, E3b1-M35 and J2-M172 show low frequencies but are more prevalent in the South, which has been interpreted to be a signal of the gene flow coming from Central European Neolithic farmers [17]. Rlal-M17 is rather rare, both in the North, where it probably originates from eastern Europe, and in the South, of possible Greek provenience [17]. Occurrence of J2-M172 Y-chromosomes in Tuscany has been related to the Etruscan heritage of the region (see [17]). The two Italian major islands, Sicily and Sardinia, show a different demographic history. The Y-chromosome variability of Sicily shares a common history with that of southern Italy, enriched by an additional Arab contribution, but also North African and Greek influences [18]. On the other hand, Sardinia has been considered to be a genetic outlier within Europe showing clear signals of founder effects; some scholars suggest that its peoples could be of ancient Iberian origin [19]; recent genetic studies point to genetic contribution coming from southern France [20].

On the other hand, mitochondrial DNA studies show that Italy does not differ too much from other European populations; however, some populations have the same peculiarities and preserve signals of the ancient past demographic event, such as the Tuscans [8,9], or the Ladins [7,21,22]. Recently, patterns of variation observed in haplogroup U5b3 demonstrated for the first time the existence of a North Italian pre-historical human refuge from the hostile Central European regions covered by the ice of the Last Glacial Maximum period [20]; this area, as was also the Franco-Cantabrian region [23-26], served as a region of European repopulation during the beginning of the Holocene.

The main aim of the present study was comprehensively to analyze the patterns of mtDNA and Y-chromosome variation in Italy. This study differs from previous ones in that: (1) it provides mtDNA data from 12 new sample populations from Italy; (2) we analyzed two linguistic isolates, Ladin and Grecani Salentini, the latter sampled for the first time in this study; (3) we analyzed a sample population from Lucera (Southern Italy) for the first time, a population that according to documentation received an important input of North African immigrants during the thirteenth century; (4) we analyzed the patterns of mtDNA variation in Italy globally, that is, by combining more than 3,700 control region profiles from the literature (41 population samples in total) coupled with the more than 580 new profiles provided here; (5) Ychromosome haplotype and haplogroup patterns are analyzed in 
parallel with the mtDNA data in order to determine the possible differences that occurred historically in the male versus female demographic movements; and (6) the influx of migrants from Africa (North and sub-Saharan) and other regions is also analyzed using phylogeographic inferences, and also a model of admixture based on haplotypic data and a panel of ancestry informative markers (AIMs).

\section{Materials and Methods}

\section{Ethics statement}

Written informed consent was obtained from all sample donors. Analysis of mtDNA sequences was approved by the institutional review boards of the Università Cattolica del Sacro Cuore (Roma). Moreover, the study conforms to the Spanish Law for Biomedical Research (Law 14/2007- 3 of July).

\section{Samples}

A total of 583 individuals were sampled from along the Italian Peninsula, representing 12 different populations (Figure 1), two of them (Ladin and Grecani Salentini) being linguistic isolates, and the Lucera being a historical enclave of Arabs coming from North Africa. A brief description of these latter three populations is given below.

In the Italian territory, the Alpine arc represents one of the main areas of presence of alloglot populations, some of them biologically isolated for historical and geographic reasons [27]. At the end of the medieval period $(\sim 1200 \mathrm{AD})$ and especially in the valley zone, a first colonization of native peasants began, starting with the use of lands previously exploited only for pasture and the lumber. Successively, with different modalities and under the control of laic and ecclesiastical owners, the colonization process involved migrant nuclei from the Tyrol, Carinthian area and other zones [28]. Currently, the Alpine arc populations are differentiated with a remarkable cultural diversity that is well represented by linguistic elements. Thus, besides the official main languages, numerous minority languages or dialects are also the cultural patrimony of linguistic minorities [27,29]. Ladin is often attributed to be a relic of vulgar Latin dialects associated with Rhaeto-Romance languages. In the vast multi-ethnic Holy Roman Empire, and then after 1804 the Austrian empire, the Ladins were left in relative peace and were allowed to continue the use of their language and culture.

Grecani Salentini is a Hellenic-speaking linguistic island of Salento, situated in southern Puglia, and consisting of nine municipalities in which a neo-Greek dialect, also known as Grecanic or Griko, is spoken. The origins of this linguistic island in Salentine Greece are uncertain. The German linguist G. Rohlfs proposed its origin in the Magna Graecia region; while O. Parlangeli suggests a Byzantine derivation of the Griki of Salento. Greek researchers (e.g. A. Karanastasis) claim the input of Byzantine elements in the pre-existing Magna Graecia matrix. The Greek arrival in the Salentine Peninsula occurred both in the Magna Graecia, and posterior Byzantine dominations. The numerous villages of Grecani Salentini had a Greek culture and language and practiced the Greek-orthodox religion. In the beginning of the Norman conquest (eleventh century), and more intensively with the arrival of different casati (clans) (Svevian, Angioin, Aragones, etc), the catholic clergy supplanted those of the orthodox faith [30].

The Lucera population has received an important influx from North African Arab peoples (see [31]). Thus, after the collapse of the Roman Empire in Europe, the Arab domination spread into the Mediterranean Basin. Referred to either as Moors in Iberia or
Saracens in Southern Italy and Sicily, Arabs arrived in Europe in $711 \mathrm{AD}$, and in $831 \mathrm{AD}$ Iberia and Sicily were almost completely subjected to Arab domination [31]. In the thirteenth century, Frederick II moved the Sicilian Arabs to the city of Lucera (North Apulia) [32]. This sample was genotyped for STRs and Ychromosome SNPs in Capelli et al. [31]

To the best of our knowledge, all individuals collected in the present study were not maternally and paternally closely related; they had different surnames and all the donors referred back at least two generations in the region where the samples were collected.

All the samples were analyzed for the control region and selected mtSNPs (see below). A subset of the samples comprised unrelated males $(n=292)$ representing seven different populations. These samples were genotyped for a panel of 17 Y-chromosome SNPs (see below), and were previously genotyped for the Yfiler [33]. In addition, autosomal ancestry informative markers (AIMs) were genotyped in 441 individuals (see below).

\section{DNA extraction}

Blood extraction was performed with a salting-out method [34], modified and re-adapted to buccal cells. Swabs were incubated in $500 \mu \mathrm{l}$ of 0.2 sodium acetate, $35 \mu \mathrm{l}$ of $10 \%$ SDS and $20 \mu \mathrm{l}$ of $20 \mathrm{mg} / \mathrm{ml}$ Proteinase $\mathrm{K}$ for 16 hours at $56^{\circ} \mathrm{C}$. They were then removed and $500 \mu \mathrm{l}$ of $3 \mathrm{M} \mathrm{NaCl}$ solution was added. Proteins were removed by centrifugation, and the DNA precipitated by adding $1 \mathrm{ml}$ of ethanol $100 \%$ at $-20^{\circ} \mathrm{C}$ for a few hours. After centrifugation, the DNA pellet was twice washed with ethanol $70 \%$, dried and re-suspended in water. For the blood samples, aliquots of $500 \mu \mathrm{l}$ each were thawed and red cells selectively lysed by a $1 \times$ lysis buffer. After three washes with the lysis buffer, white cells were pelleted and the DNA extracted using the salting-out protocol. All the samples were quantified by direct comparison with standard on agarose $1 \%$ minigels $(1 \mathrm{~g}$ of agarose in $100 \mathrm{ml}$ of TBE 1X-from the 1:10 diluition of TBE 10X).

\section{PCR and mtDNA control region sequencing}

MtDNA has been sequenced for the complete control region, from position 16024 (in HVS-I) to 569 (in HVS-II). The first and second hypervariable regions (HVS-I/II) were amplified via the polymerase chain reaction (PCR) and using primers reported by Álvarez-Iglesias et al. [35].

PCR was carried out in a $25 \mu \mathrm{l}$ reaction mix with $1 \times$ reaction buffer (20 mM Tris-HCl, ph 8.0, 0.1 mM EDTA, $1 \mathrm{mM}$ DDT, $50 \%$ (v/v) glycerol), $1.5 \mathrm{mM} \mathrm{MgCl}_{2}, 200 \mathrm{mM}$ each dNTP, $0.4 \mu \mathrm{M}$ each primer, $2.5 \mathrm{U}$ (Units). Taq polymerase and $0.1-$ $1 \mathrm{ng}$ DNA template was added to the reaction mixture (Taq DNA Polymerase, recombinant. INVITROGEN ${ }^{\circledR}$ Corporation). Amplification was carried out in a GENE AMP ${ }^{\circledR}$ PCR SYSTEM 9700 (Applied Biosystems, Foster City, California,U.S.A.) using a hot start at $95^{\circ} \mathrm{C}$ for $1 \mathrm{~min}$, followed by 36 cycles at $95^{\circ} \mathrm{C}$ for $30 \mathrm{sec}, 55^{\circ} \mathrm{C}$ for $60 \mathrm{sec}$, and $72^{\circ} \mathrm{C}$ for $30 \mathrm{sec}$ and a final extension at $72^{\circ} \mathrm{C}$ for $15 \mathrm{~min}$. Before the sequencing reaction, PCR products were checked by electrophoresis in polyacrylamide non-denaturing gel (T9, C5), and subsequently the gel was stained with silver nitrate. PCR products were then purified with a MultiScreen ${ }^{\circledR}$ PCR $_{\mu 96}$ Plate (Millipore, Bedford, Ma 01730, U.S.A), 96-well device.The vacuum-based, size exclusion separation effectively and quickly removed the containing salts, unincorporated dNTPs and primers from PCR reactions. Cycle sequencing was performed on both strands in a GENE AMP ${ }^{\circledR}$ PGR SYSTEM $9700(\mathrm{AB})$ thermal cycler using the ABI Prism ${ }^{\circledR}$ dRhodamine Terminator Cycle Sequencing Ready Reaction Kit (AB). This kit consists of a reaction mix composed of: DNA-modified and 


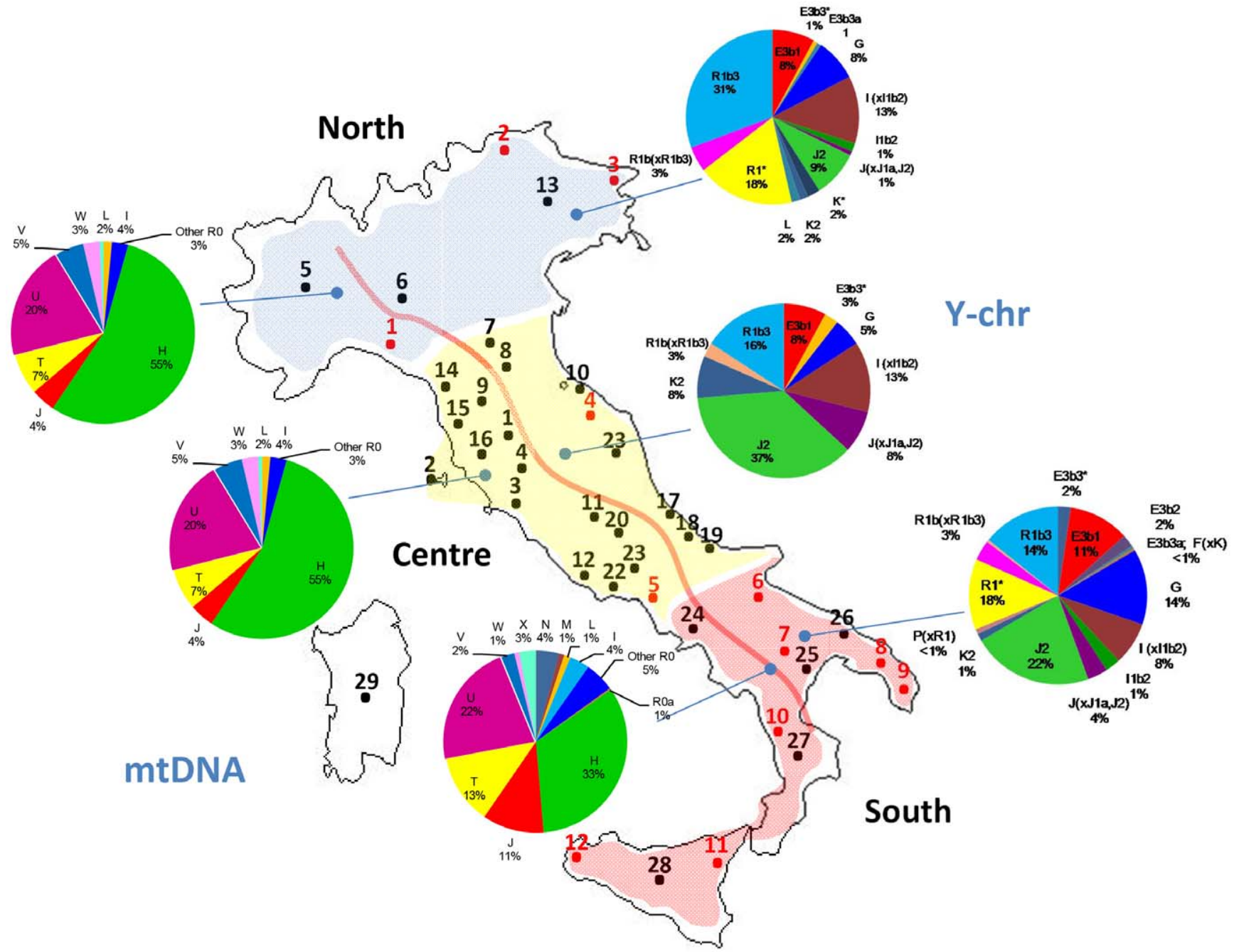

Figure 1. Map showing the location of the samples analyzed in the present study and those collected from the literature (see Table 1). Pie charts on the left display the distribution of mtDNA haplogroup frequencies, and those on the right the Y-chromosome haplogroup frequencies.

doi:10.1371/journal.pone.0050794.g001

termostable polymerase, Buffer Tris-HCl (pH 9.0), $\mathrm{MgCl}_{2}$, dNTPs, dichlororhodamine-marked ddNTPs. An aliquote of $30 \mathrm{ng}$ amplicon and $3.2 \mathrm{\rho M}$ primers were added to a $2 \mu \mathrm{l}$ reaction mix. Sequencing was carried out using a hot start at $96^{\circ} \mathrm{C}$ for $4 \mathrm{~min}$, followed by 36 cycles at $96^{\circ} \mathrm{C}$ for $15 \mathrm{sec}, 50^{\circ} \mathrm{C}$ for $10 \mathrm{sec}, 60^{\circ} \mathrm{C}$ for $2 \mathrm{sec}$ and a final extension at $60^{\circ} \mathrm{C}$ for $10 \mathrm{~min}$. The removal of excess dideoxy terminators, primers and buffer was accomplished with an alcoholic purification.

The sequence products were denatured with deionized formamide and analyzed by capillary electrophoresis on an ABI PRISM $3130^{\circledR}$ Genetic Analyzer (AB).The resulting data were analyzed with PE/ABD software Sequencing Analysis 5.2 and sequences were aligned and compared with the Cambridge sequence [36] from position 16024 tol6569 for HVS-I and from position 1 to 600 for HVS-II by the SeqScape v.2.0 (AB).

\section{Analysis of mtDNA coding region SNPs}

Biallelic markers were genotyped using a multiplex approach [37]. The selected SNPs were combined into two multiplex reactions. Multiplex 1 included a selection of SNPs defining common European haplogroups [38]. Multiplex 2 included exclusively polymorphisms defining sub-lineages inside haplogroup H. Primers were designed in order to adjust the annealing temperatures and amplicon lengths to allow analysis in multiplex reactions [37]. The sizes of the PCR products ranged from 80 to $224 \mathrm{bp}$.

Both multiplexes were performed using $10 \mathrm{ng}$ of DNA template in a $25 \mu \mathrm{l}$ reaction volume comprising $1 \times$ Taq Gold Buffer $(\mathrm{AB})$, $200 \mu \mathrm{M}$ of each dNTP, $2 \mathrm{mM} \mathrm{MgCl}_{2}$ and $0.5 \mathrm{U}$ of AmpliTaq Gold Polymerase (AB). For the primer concentrations, see [37].

Amplification was carried out using a GENE AMP ${ }^{\circledR}$ PCR SYSTEM $9700(\mathrm{AB})$ thermocycler. After a $95^{\circ} \mathrm{C}$ pre-incubation step for $11 \mathrm{~min}, \mathrm{PCR}$ was performed for a total of 32 cycles using the following conditions: $94^{\circ} \mathrm{C}$ denaturation for $30 \mathrm{sec}$, annealing at $60^{\circ} \mathrm{C}$ for $30 \mathrm{sec}$ and extension at $72^{\circ} \mathrm{C}$ for $1 \mathrm{~min}$, followed by a 15 min final extension at $72^{\circ} \mathrm{C}$. PGR products were checked by polyacrylamide gel electrophoresis (T9, C5) visualized by silver staining.

After amplification, PCR products required purification to remove primers and unincorporated dNTPs. Post-PCR purification was performed with ExoSapIT (Amershan Pharmacia Biotech): $1 \mu \mathrm{l}$ of PCR product was incubated with $0.5 \mu \mathrm{l}$ of 
ExoSapIT for $15 \mathrm{~min}$ at $37^{\circ} \mathrm{C}$ followed by $15 \mathrm{~min}$ at $80^{\circ} \mathrm{C}$ for enzyme inactivation. The minisequencing reaction was performed in a GENE AMP $^{\circledR}$ PCR SYSTEM $9700(\mathrm{AB})$ thermocycler following the recommendations of the manufacturer: $2 \mu \mathrm{l}$ of $\mathrm{SNaPshot}$ ready reaction mix, $0.2 \mu \mathrm{M}$ of extension primer for each SNP (see [37]) and $1 \mu \mathrm{l}$ of both purified PCR products in a total volume of $7 \mu \mathrm{l}$. The reaction mixture was subjected to 25 single base extension cycles of denaturation at $96^{\circ} \mathrm{C}$ for $10 \mathrm{sec}$, annealing at $50^{\circ} \mathrm{C}$ for $5 \mathrm{sec}$ and with an extension at $60^{\circ} \mathrm{C}$ during $30 \mathrm{sec}$. After minisequencing reactions, a post-extension treatment to remove the 5'-phosphoryl group of ddNTPs aided the prevention of co-migration of unincorporated ddNTPs with extended primers and production of a high background signal. The final volume $(7 \mu \mathrm{l})$ was treated with $0.7 \mu \mathrm{l}$ of SAP (Amersham Biosciences) for $60 \mathrm{~min}$ at $37^{\circ} \mathrm{C}$, followed by $15 \mathrm{~min}$ at $80^{\circ} \mathrm{C}$ for enzyme inactivation.

The minisequencing products $(1.5 \mu \mathrm{l})$ were mixed with $10 \mu \mathrm{l}$ of $\mathrm{HiDi}^{\mathrm{TM}}$ formamide and $0.2 \mu \mathrm{l}$ of GeneScan-120 LIZ size standard $(\mathrm{AB})$ and electroforesis was performed on an $\mathrm{ABI}$ PRISM $3130{ }^{\circledR}$ Genetic Analyser (AB). The resulting data was analyzed with Gene Mapper ID.

\section{Minisequencing of SNPs characterizing additional typical European haplogroups}

Samples that were determined (using the SNP panel above) as being derived from J/T (T14766C; C7028T; T4216C), U (T14766C; C7028T; A12308G) and the U-subclade K (T14766C; C7028T; A12308G; A10398G), were further genotyped using an additional set of 14 haplogroup-specific SNP markers that identify the following sub-branches: J1 (G3010A), J1b (G3010A; C13879T), J1c (G3010A; G114798T), J2 (G15257A), T2a (A14687G), T2b (G5147A), U5a (A14793G), U5al (A14793G; Al5218G), U5b (A7768G), U5bl (A7768G; A5656G), U5b2 (A7768G; C1721T), K1 (T14798C; T1189C), K1a (T14798C; T1189C; C0497T) and K2 (T14798C; T1189C; T9716C). PCR and minisequencing reactions were performed as described above. For PCR and minisequencing primer concentrations, see Table S1.

\section{Genotyping of Y-SNPs}

Biallelic markers were genotyped using a multiplex approach [39]. A set of 30 SNPs was tested, allowing assignation of the analyzed $\mathrm{Y}$-chromosome to haplogroups $(\mathrm{Hg})$, following the nomenclature and the phylogenetic relationships defined from the Y Chromosome Consortium [40]. The selected method for allele discrimination was a single base extension reaction using the SNaPshot multiplex kit (AB). We added the M269 marker to the first of the four multiplexes, in order better to dissect the subhaplogroup R1b (R1b3). The primers of this marker were M269-F 5'-TCA TGC CTA GCA TCA TTG CT-3' and M269-R 5'TCT TTT GTG TGG CTT CTG AGG-3', and the minisequencing primer 5'-GGA ATG ATG AGG GTT TGG TTA AT-3'.

\section{Genotyping of AIMs}

A panel of 52 AIMs were genotyped according to Sánchez et al. [41] in a subset of 441 individuals. Several other population datasets were used for inter-population comparisons. This data corresponded to the CEPH panel (http://www.cephb.fr/en/ cephdb/) as reported in HapMap (http://hapmap.ncbi.nlm.nih. gov/) and was collected using the data-mining tool SPSmart $[42,43]$; it includes population samples from all over the world (Africa, Europe, Asia, etc.); see legend of Figure 2 for more information.

\section{Statistical analysis}

A total of 42 Italian population samples were analyzed for mtDNA in the present study. Comparative inter-population analyses were also carried out for the HVS-I segment ranging from 16024 to 16365 , since this is the analyzed segment common to all of them. Haplotype $(H)$ and nucleotide diversity $(\pi)$ and other diversity indices [44-46] were computed using DnaSP 4.10.3 software [47]. Problematic variation located around 16189, usually associated to length heteroplasmy e.g. 16182G or 16183C, was ignored. Analysis of molecular variance (AMOVA) was carried out using Arlequin 3.5. [48]. Nomenclature of mtDNA lineages followed previous studies e.g. [23,25,38,49,50]; see Phylotree for a compilation of the worldwide phylogeny and an update of the nomenclature based on entire mtDNA genomes [51]. Genotyping and documentation errors were monitored following the phylpogenetic principles previously applied e.g. [5259].

Mitochondrial DNA and Y-chromosome data was collected from the literature. The mtDNA data generated in the present study was analyzed together with 3,834 mtDNA HVS-I Italian profiles collected from the literature (Table S2; 76 sample populations). The Y-SNPs were analyzed together with 1,251 Italian profiles reported in the literature (16 population samples). A full list of references for all the data used in the present study is given in Table S2.

Haplogroup frequencies were estimated by chromosome counting. Statistical differences in haplogroup frequencies were evaluated using a Pearson's chi- square test and by setting up the nominal significant value $\alpha$ as 0.05 .

Finally, classification of mtDNA sequences into haplogroups was performed following phylogenetic criteria (Phylotree Build 14, http://www.phylotree.org/) and using both the control region sequence profile and mtSNPs.

\section{Results}

\section{Molecular diversity of mtDNA and Y-chromosome Italian profiles}

Diversity indices were computed for all the populations analyzed in the present study and also in those Italian populations samples reported in the literature (Tables 1 and 2). Population samples were also grouped in main regions (North, Central, South, West, and East) in order to investigate the role of geography in the distribution of mtDNA variation.

Mitochondrial DNA haplotypes for the samples analyzed in the present study are reported in Table S3. Table 1 shows the molecular diversity values based on mtDNA data for 41 Italian population samples. The values indicate that the Isle of Elba is, by far, the Italian population sample that shows the lowest diversity for all the indices computed, probably as a consequence of its relative isolation from the country. It has been reported that this was a well-known enclave of Etruscan influence, and some mtDNA particularities have been described before [8,9]. Alternatively, low molecular diversity could be due to low sample sizes, although this fact is mirrored in the standard deviation of the different estimates. Excluding the Isle of Elba, haplotype diversity in Italy ranges from 0.834 to 1 , nucleotide diversity from 0.01003 to 0.02409 , and the average value of nucleotide differences from 3.4 to 8.19 (a value that is correlated with the nucleotide diversity). In general, Italy shows some level of heterogeneity when examined for diversity values.

When grouping populations by main geographical regions, it can be observed that Central Italy has slightly lower values than North and South Italy for all the indices computed (Table 1). The 

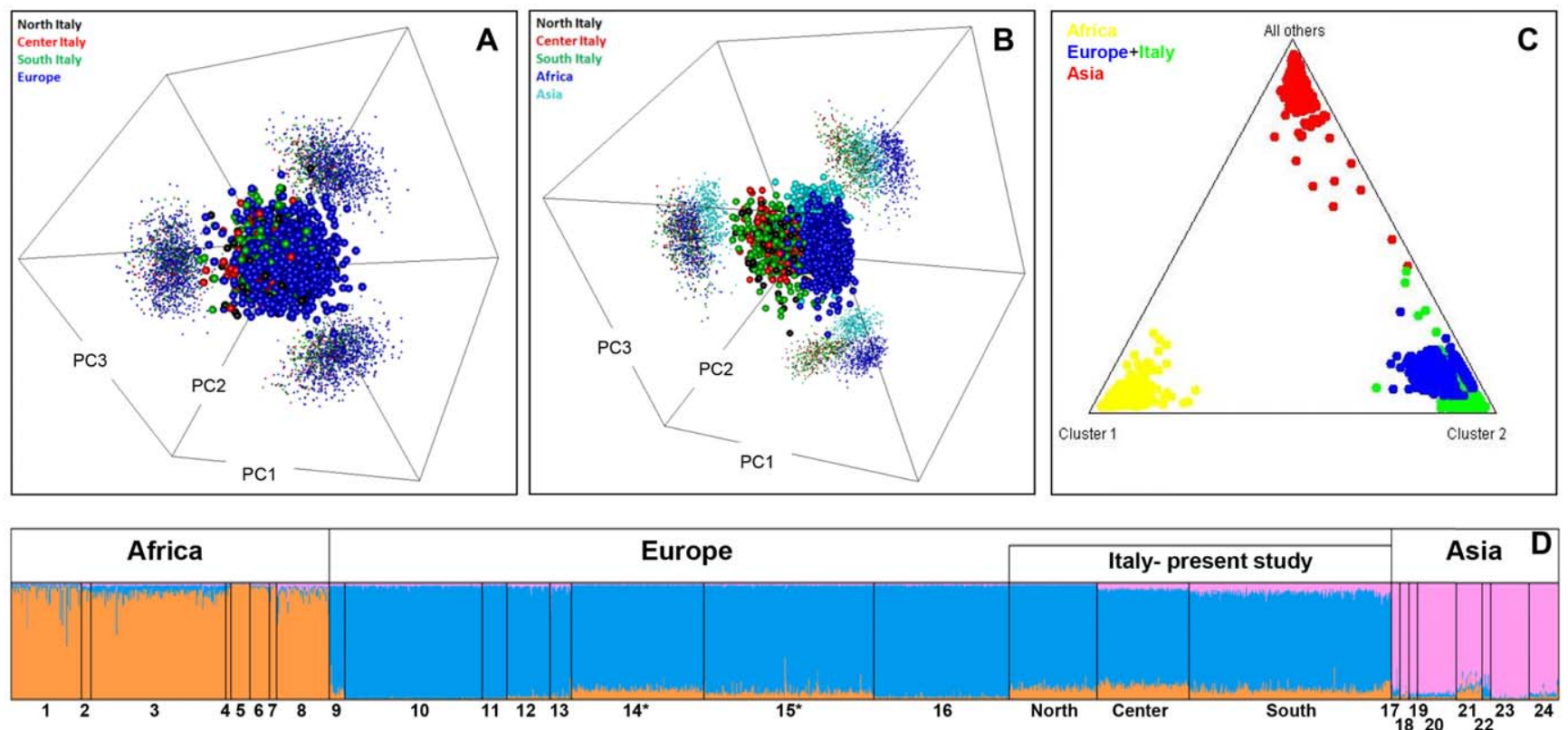

Figure.......D: 1-Angola; 2-Kenya-Bantu NE; 3-Mozambique; 4-Namibia-San; 5-Nigeria-Yoruba; 6-Senegal-Mandenka; 7-South Africa-Bantu; 8-Uganda; 9-Britain; 10-Denmark; 11-French; 12-Germany; 13-Ireland; 14*-NW Spain; 15*-Portugal; 16-Slovenia; 17-China-Dai; 18-China-Daru; 19-China-Han 20-China-Hezhen; 21-Japanese; 22-Mongolia; 23-Taiwan; 24-Thailand (* Mediterranean countries)

Figure 2. Analysis of AIMs in Italian populations versus other continental population groups. (A) PCA of Italian populations divided into the main regions North, Center and South (as analyzed in the present study) and other European populations; (B) the same Italian populations plus sub-Saharan African, and Asian populations; (C) triangle plot as obtained using STRUCTURE analysis of Italian, European, sub-Saharan, and Asian populations; (D) bar plot of ancestral membership values as obtained using STRUCTURE analysis of the same populations used in (C). Population codes: 1: Angola; 2: Kenya-Bantu NE; 3: Mozambique; 4: Namibia-San; 5: Nigeria-Yoruba; 6: Senegal-Mandenka; 7: South Africa-Bantu; 8: Uganda; 9: Britain; 10: Denmark; 11: French; 12: Germany; 13: Ireland; 14*: NW Spain; 15*: Portugal; 16: Slovenia; 17: China-Dai; 18: China-Daru; 19: China-Han; 20: China-Hezhen; 21: Japanese; 22: Mongolia; 23: Taiwan; 24: Thailand. Genotypes were downloaded using the method in [43,83] and belong to the $\mathrm{CEPH}$ panel. An asterisk indicates Mediterranean populations. doi:10.1371/journal.pone.0050794.g002

higher diversity values were found in South Italy. Diversity values are however very similar when examining populations located in West Italy versus those in the East. The inclusion of Sicily (as part of South Italy) in the computation does not substantially change these estimates (Table 1).

Y-SNP data were obtained for all the samples analyzed in the present study (Table S4). Table 2 shows the diversity indices for the Y-SNPs in different Italian populations. The Y-STR diversity values for the samples analyzed in the present study and other Italian and European samples have already been reported in Brisighelli et al. [33]. As expected, diversity values of Y-SNP haplogroup patterns are lower than those obtained for the mtDNA haplotypes given that the indices are based on haplogroup and not on Y-STR haplotypes. In fact, values based on Y-STR profiles (minimum or extended Yfiler profiles) [33] are higher than those observed for the HVS-I profiles. Ladins are among the populations with the lowest Y-SNP diversity values, while the Grecani Salentini show diversity values that are comparable to other Italian samples. Modena shows remarkable low haplotype diversity values.

\section{Phylogeography}

The mtDNA haplogroup make-up of Italy as observed in our samples fits well with expectations in a typical European population. Thus, most of the Italian mtDNAs $(\sim 89 \%)$ could be attributed to European haplogroups $\mathrm{H}(\sim 40 \%), \mathrm{I}(\sim 3 \%), \mathrm{J}(\sim 9 \%)$, $\mathrm{T}(\sim 11 \%), \mathrm{U}(\sim 20 \%$; U minus U6), V $(\sim 3 \%), \mathrm{X}(\sim 2 \%)$ and $\mathrm{W}$ $(\sim 1 \%)$; Figure 1. There are however important differences in haplogroup frequencies when examining them by main geograph- ical regions. Thus, for instance, haplogroup $\mathrm{H}$ is $59 \%$ in the North, $46 \%$ in the Center, and decays to $\sim 33 \%$ in the South; moreover, these regional differences are statistically significant: North vs South (Pearson's chi-square, unadjusted- $P$ value $<0.00003$ ), and Center vs South (Pearson's chi-square, unadjusted- $P$ value $<0.03724$ ).

Mitochondrial DNA haplotypes of African origin are mainly represented by haplogroups M1 (0.3\%), U6 (0.8\%) and L (1.2\%); from here onwards, $\mathrm{L}$ will be used to refer to all mtDNA lineages, excluding the non-African branches $\mathrm{N}$ and $\mathrm{M}[60,61]$.

A total of $282 \mathrm{Y}$-chromosomes were analyzed for a set of YSNPs and were classified into 22 different haplogroups (Figure 3). Two haplogroups were not found, even though markers defining these clades were tested: N3 and Rlal. Five haplogroups represented $76.71 \%$ of the total chromosomes: R1b3, J2, $\mathrm{I}(\mathrm{xI} 1 \mathrm{~b} 2)$, E3b1 and G. The frequencies averaged across populations were $26 \%, 21.2 \%, 10.2 \%, 9.9 \%$ and $9.2 \%$, respectively. The remaining haplogroups sum to $23.2 \%$ in the total sample, and never above $4 \%$ in single population samples.

R1b3 frequency was found to be higher in the northern part of the country, while the Y-chromosome haplogroups G and E3b1, $\mathrm{J} 2$ and $\mathrm{I}(\mathrm{xI} 1 \mathrm{~b} 2)$ frequencies were higher in the south and in the central part of the country, respectively (Figure 1).

Regional differences are substantially higher in the Y-chromosome than in the mtDNA. Thus, for instance, haplogroup $\mathrm{R}$ in the Y-chromosome was $54 \%$ in the North, $18 \%$ in the Center, and $31 \%$ in the South. Frequency differences were statistically significant between North vs Center (Pearson's chi-square, unadjusted $-P$ value $=0.0014)$, and North vs South (Pearson's chi- 
Table 1. Diversity indices computed for different Italian regions based on HVS-I data (sequence segment 16090-16365).

\begin{tabular}{|c|c|c|c|c|c|c|c|c|c|c|}
\hline Population & Region & Pop ID & Reference & $N$ & $k$ & $k / n$ & $s$ & $h$ & $\Pi$ & $M$ \\
\hline Liguri & NW & 1 & p.s. & 50 & 40 & 0.8 & 53 & $0.962 \pm 0.021$ & $0.01426 \pm 0.0145$ & 4.875 \\
\hline Torino & NW & 5 & [84] & 50 & 45 & 0.9 & 49 & $0.993 \pm 0.007$ & $0.01483 \pm 0.0011$ & 5.056 \\
\hline Ladin & NE & 2,13 & p.s. $[22,62,63,66]$ & 504 & 170 & 0.3 & 106 & $0.960 \pm 0.005$ & $0.01251 \pm 0.0004$ & 4.252 \\
\hline Pavia & NE & 6 & [84] & 47 & 35 & 0.7 & 44 & $0.969 \pm 0.017$ & $0.01316 \pm 0.0012$ & 4.502 \\
\hline Udine & NE & 3 & p.s. & 51 & 32 & 0.6 & 38 & $0.903 \pm 0.038$ & $0.01231 \pm 0.0135$ & 4.19858 \\
\hline Arezzo/Chiusi & $C W$ & 1 & [9] & 14 & 14 & 1 & 22 & $1.000 \pm 0.027$ & $0.01488 \pm 0.0129$ & 5.088 \\
\hline Casentino & $\mathrm{CW}$ & 15 & [8] & 122 & 77 & 0.6 & 167 & $0.979 \pm 0.007$ & $0.02409 \pm 0.0082$ & 8.190 \\
\hline Collevecchio/Magliano Sabino & $\mathrm{CW}$ & 3 & [9] & 12 & 11 & 0.9 & 14 & $0.985 \pm 0.040$ & $0.01201 \pm 0.0015$ & 4.106 \\
\hline Elba & $C W$ & 2 & [9] & 16 & 6 & 0.4 & 11 & $0.683 \pm 0.120$ & $0.00853 \pm 0.0017$ & 2.908 \\
\hline Firenze & $\mathrm{CW}$ & 9 & [84] & 48 & 40 & 0.8 & 54 & $0.980 \pm 0.014$ & $0.01332 \pm 0.0012$ & 4.556 \\
\hline Jenne & $C W$ & 22 & [85] & 103 & 34 & 0.3 & 47 & $0.834 \pm 0.036$ & $0.01006 \pm 0.0360$ & 3.440 \\
\hline Latini & $C W$ & 5 & p.s. & 48 & 29 & 0.6 & 35 & $0.902 \pm 0.039$ & $0.01003 \pm 0.0010$ & 3.429 \\
\hline Latium & $C W$ & 20 & [86] & 52 & 37 & 0.7 & 48 & $0.959 \pm 0.019$ & $0.01313 \pm 0.0014$ & 4.492 \\
\hline Murlo & $C W$ & 16 & [8] & 86 & 60 & 0.7 & 68 & $0.976 \pm 0.010$ & $0.01327 \pm 0.0009$ & 4.524 \\
\hline Roma & $\mathrm{CW}$ & 12 & [84] & 58 & 49 & 0.8 & 55 & $0.987 \pm 0.008$ & $0.01433 \pm 0.0011$ & 4.901 \\
\hline Terni & $C W$ & 11 & [84] & 29 & 20 & 0.7 & 33 & $0.941 \pm 0.034$ & $0.01201 \pm 0.0014$ & 4.108 \\
\hline Tuscany & $\mathrm{CW}$ & 4 & {$[9,10,87]$} & 127 & 86 & 0.7 & 77 & $0.982 \pm 0.007$ & $0.01305 \pm 0.0075$ & 4.464 \\
\hline Vallepietra & $C W$ & 21 & [85] & 21 & 8 & 0.4 & 17 & $0.871 \pm 0.044$ & $0.01281 \pm 0.0014$ & 4.381 \\
\hline Volterra & $C W$ & 14 & [8] & 114 & 57 & 0.5 & 62 & $0.955 \pm 0.013$ & $0.01193 \pm 0.0007$ & 4.057 \\
\hline Abruzzo & CE & 17 & {$[86,88]$} & 61 & 53 & 0.8 & 62 & $0.990 \pm 0.007$ & $0.01500 \pm 0.0010$ & 5.131 \\
\hline Ancona & CE & 10 & [84] & 73 & 55 & 0.7 & 59 & $0.963 \pm 0.017$ & $0.01379 \pm 0.0010$ & 4.717 \\
\hline Bologna & CE & 7 & {$[84,89]$} & 146 & 79 & 0.5 & 64 & $0.970 \pm 0.008$ & $0.01250 \pm 0.0006$ & 4.278 \\
\hline Center East & CE & 23 & [90] & 83 & 62 & 0.7 & 60 & $0.974 \pm 0.012$ & $0.01352 \pm 0.0009$ & 4.625 \\
\hline Croatian Italians & CE & 19 & [86] & 41 & 28 & 0.7 & 46 & $0.970 \pm 0.015$ & $0.01524 \pm 0.0017$ & 5.213 \\
\hline Modena & CE & 8 & [84] & 44 & 33 & 0.7 & 43 & $0.958 \pm 0.023$ & $0.01139 \pm 0.0012$ & 3.895 \\
\hline Molise & CE & 18 & [86] & 62 & 41 & 0.6 & 58 & $0.938 \pm 0.025$ & $0.01260 \pm 0.0013$ & 4.309 \\
\hline Piceni & CE & 4 & p.s. & 53 & 43 & 0.8 & 56 & $0.985 \pm 0.009$ & $0.01306 \pm 0.0011$ & 4.414 \\
\hline Belvedere & SW & 10 & p.s. & 50 & 41 & 0.8 & 44 & $0.980 \pm 0.013$ & $0.01320 \pm 0.0010$ & 4.532 \\
\hline Calabria & SW & 27 & {$[91,92]$} & 389 & 213 & 0.5 & 128 & $0.983 \pm 0.003$ & $0.01521 \pm 0.0004$ & 5.203 \\
\hline Campania & SW & 30 & [86] & 48 & 41 & 0.8 & 59 & $0.980 \pm 0.014$ & $0.01519 \pm 0.0014$ & 5.166 \\
\hline Catania & SW & 11 & p.s. & 40 & 35 & 0.9 & 45 & $0.990 \pm 0.010$ & $0.01460 \pm 0.0012$ & 4.979 \\
\hline Sicily & SW & 28 & {$[38,93-96]$} & 558 & 240 & 0.4 & 125 & $0.958 \pm 0.006$ & $0.01289 \pm 0.0004$ & 4.343 \\
\hline Trapani & SW & 12 & p.s. & 40 & 30 & 0.7 & 36 & $0.977 \pm 0.013$ & $0.01313 \pm 0.0013$ & 4.465 \\
\hline Apulia & SE & 26 & [86] & 26 & 24 & 0.9 & 43 & $0.991 \pm 0.015$ & $0.01550 \pm 0.0022$ & 5.304 \\
\hline Basilicata & SE & 25 & [91] & 92 & 65 & 0.7 & 70 & $0.983 \pm 0.007$ & $0.01290 \pm 0.0008$ & 4.428 \\
\hline Grecani Salentini & SE & 8 & p.s. & 47 & 37 & 0.8 & 44 & $0.989 \pm 0.007$ & $0.01310 \pm 0.0011$ & 4.480 \\
\hline Lucera & SE & 6 & p.s. & 60 & 42 & 0.7 & 55 & $0.976 \pm 0.011$ & $0.01345 \pm 0.0011$ & 4.586 \\
\hline South Apulia & SE & 9 & p.s. & 53 & 38 & 0.7 & 49 & $0.973 \pm 0.014$ & $0.01579 \pm 0.0010$ & 5.401 \\
\hline Sanniti & SE & 7 & p.s. & 50 & 41 & 0.8 & 49 & $0.988 \pm 0.008$ & $0.01420 \pm 0.0013$ & 4.843 \\
\hline Sardinia & - & 29 & {$[38,87,97]$} & 351 & 171 & 0.4 & 98 & $0.950 \pm 0.009$ & $0.01183 \pm 0.0004$ & 4.033 \\
\hline \multicolumn{11}{|l|}{ Geographical region } \\
\hline North Italy & - & - & & 702 & 267 & 0.4 & 126 & $0.963 \pm 0.004$ & $0.01282 \pm 0.0004$ & 4.295 \\
\hline Central Italy & - & - & & 1413 & 500 & 0.4 & 216 & $0.958 \pm 0.004$ & $0.01243 \pm 0.0002$ & 4.113 \\
\hline South Italy & - & - & & 1453 & 569 & 0.4 & 183 & $0.973 \pm 0.002$ & $0.01368 \pm 0.0002$ & 4.541 \\
\hline West Italy (without Sicily) & - & - & & 1437 & 578 & 0.4 & 232 & $0.969 \pm 0.003$ & $0.01315 \pm 0.0002$ & 4.405 \\
\hline West Italy (with Sicily) & - & - & & 2075 & 709 & 0.3 & 236 & $0.963 \pm 0.003$ & $0.01260 \pm 0.0002$ & 4.133 \\
\hline East Italy & - & - & & 1493 & 520 & 0.3 & 165 & $0.964 \pm 0.003$ & $0.01277 \pm 0.0002$ & 4.200 \\
\hline
\end{tabular}

$\mathrm{NW}=$ North-West $\mathrm{NE}=$ North-East; $\mathrm{CW}=$ Center-West; $\mathrm{CE}=$ Center-East; $\mathrm{SW}=$ South-West; $\mathrm{SE}=$ South-East; $N=$ sample size; $\mathrm{k}=$ number of different haplotypes; $\mathrm{S}=$ segregating sites; $\mathrm{h}=$ haplotype diversity; $\pi=$ nucleotide diversity; $\mathrm{M}=$ average number of nucleotide differences.

doi:10.1371/journal.pone.0050794.t001 
Table 2. Diversity indices computed for different Italian regions based on Y-SNPs.

\begin{tabular}{|c|c|c|c|c|c|c|}
\hline Population & Region & Reference & $N$ & $k$ & $k / n$ & Gene Diversity \\
\hline Liguria & NW & Present study & 46 & 9 & 0.19 & $0.7662 \pm 0.0502$ \\
\hline Ladin & NE & [14] & 34 & 6 & 0.17 & $0.5348 \pm 0.0979$ \\
\hline Udine & NE & Present study & 47 & 10 & 0.21 & $0.7761 \pm 0.0441$ \\
\hline Central Tuscany & CW & [14] & 40 & 8 & 0.20 & $0.7397 \pm 0.0616$ \\
\hline Elba Island & CW & [14] & 94 & 7 & 0.07 & $0.6742 \pm 0.0445$ \\
\hline Latini & CW & Present study & 44 & 11 & 0.25 & $0.8256 \pm 0.0395$ \\
\hline Latium & CW & [14] & 43 & 9 & 0.20 & $0.8026 \pm 0.0388$ \\
\hline Tuscany-Latium border & $C W$ & [14] & 76 & 7 & 0.09 & $0.7554 \pm 0.0350$ \\
\hline Central Marche & CE & [14] & 59 & 7 & 0.11 & $0.7294 \pm 0.0364$ \\
\hline Marche & CE & [11] & 162 & 13 & 0.08 & $0.8489 \pm 0.0152$ \\
\hline Marche-Appennine & CE & [14] & 25 & 7 & 0.28 & $0.8033 \pm 0.0514$ \\
\hline Modena & CE & [98] & 62 & 8 & 0.12 & $0.5320 \pm 0.0743$ \\
\hline Piceni & CE & Present study & 38 & 9 & 0.23 & $0.8208 \pm 0.0450$ \\
\hline Rimini-Val Marecchia & CE & [99] & 163 & 12 & 0.35 & $0.6990 \pm 0.0308$ \\
\hline Belvedere & SW & Present study & 27 & 9 & 0.33 & $0.8547 \pm 0.0477$ \\
\hline East Campania & SW & [14] & 46 & 7 & 0.15 & $0.6870 \pm 0.0618$ \\
\hline Sicily & SW & Present study & 57 & 12 & 0.21 & $0.8327 \pm 0.0311$ \\
\hline West Campania & SW & [14] & 80 & 10 & 0.12 & $0.8446 \pm 0.0224$ \\
\hline West Calabria & SW & [14] & 57 & 7 & 0.12 & $0.7525 \pm 0.0307$ \\
\hline Sanniti & SE & Present study & 30 & 10 & 0.33 & $0.8644 \pm 0.0409$ \\
\hline Grecani Salentini & SE & Present study & 47 & 7 & 0.14 & $0.8122 \pm 0.0242$ \\
\hline Lucera & SE & [31] & 60 & 9 & 0.15 & $0.8365 \pm 0.0236$ \\
\hline South Apulia & SE & [14] & 49 & 9 & 0.18 & $0.8529 \pm 0.0237$ \\
\hline Sardinia & & [100] & 336 & 14 & 0.04 & $0.8098 \pm 0.0136$ \\
\hline \multicolumn{7}{|l|}{ Geographical region } \\
\hline North Italy & - & - & 127 & 14 & 0.11 & $0.8400 \pm 0.0189$ \\
\hline Central Italy & - & - & 806 & 21 & 0.03 & $0.8870 \pm 0.0053$ \\
\hline South Italy & - & - & 453 & 20 & 0.04 & $0.8909 \pm 0.0060$ \\
\hline West Italy (without Sicily) & - & - & 553 & 17 & 0.03 & $0.8567 \pm 0.0094$ \\
\hline West Italy (with Sicily) & - & - & 610 & 20 & 0.03 & $0.8705 \pm 0.0078$ \\
\hline East Italy & - & - & 776 & 22 & 0.02 & $0.9034 \pm 0.0037$ \\
\hline
\end{tabular}

Codes are as in Table 1.

doi:10.1371/journal.pone.0050794.t002

square, unadjusted- $P$ value $<0.00004)$. Haplogroup J2 also revealed important regional differences; it added to $9 \%$ in the North, $37 \%$ in the Center, and $22 \%$ in the South, with statistically significant differences between the North vs Center (Pearson's chisquare, unadjusted- $P$ value $<0.00002$ ), North vs South (Pearson's chi-square, unadjusted- $P$ value $<0.00148)$, and in the limit of significance Center vs South (Pearson's chi-square, unadjusted- $P$ value $<0.049$ ).

\section{Autosomal ancestry in Italy}

A panel of 52 AIMs was genotyped in 435 Italian individuals in order to estimate the proportion of ancestry from a three-way differentiation: sub-Saharan Africa, Europe and Asia. Structure analyses allowed us to infer membership proportions in population samples, and these proportions can be graphically displayed, as in

Figure 2. This analysis indicated that Italians have a basal proportion of sub-Saharan ancestry that is higher $(9.2 \%$, on average) than other central or northern European populations $(1.5 \%$, on average). The amount of African ancestry in Italians is however more comparable to (but slightly higher than) the average in other Mediterranean countries $(7.1 \%)$. Figure 2 shows in a triangle plot the relationships of Italians compared to other European, African and Asian populations.

PCA observations confirmed the results from Structure analysis, clustering Italian profiles tightly with other European ones. Thus, PCA indicated that North, Central and South Italy do not show differences between them, nor from other European populations (Figure 2). PGA also indicated clear-cut differences between Italians, Africans and Asians (Figure 2).

\section{AMOVA}

AMOVA analyses were carried out following different grouping schemes. The samples were pooled into a single population, but also by considering main Italian regions. Analyses were carried out over haplogroups and haplotypes of the Y-chromosome and the mtDNA (Table 3).

AMOVA indicated that, among populations, variance was more strongly stratified for the Y-chromosome than for the 


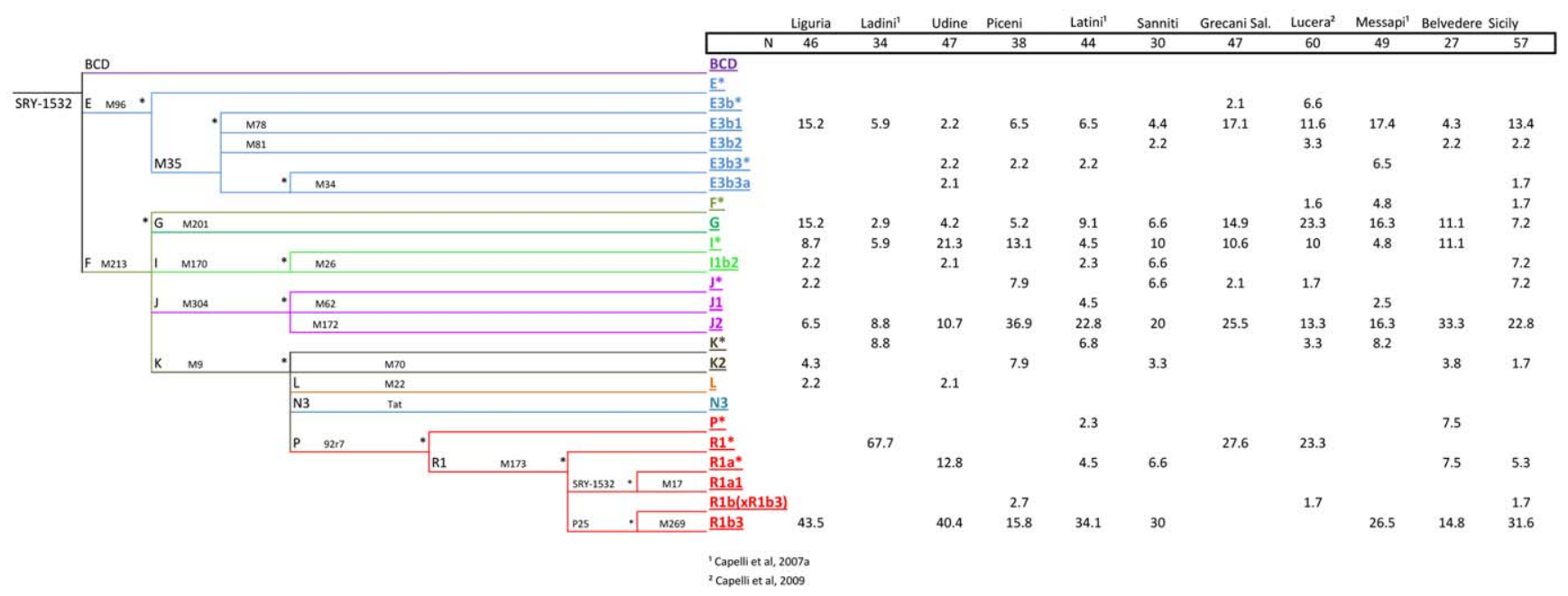

Figure 3. Phylogeny of Y-chromosome SNPs and haplogroup frequencies in different Italian populations. doi:10.1371/journal.pone.0050794.g003

mtDNA; the difference was much more marked for the analysis based on haplogroups $(14.39 \%$ vs $1.17 \%)$ than for the analysis based on haplotypes $(2.34 \%$ vs $0.79 \%)$. Among population variance was very low when analyzing main geographical regions; however, it was the latitude (North vs Center vs South) that appeared to account for higher values of among-population variance rather than longitude (West vs East), with the exception of the Y-chromosome haplogroups (although the values are below 1\%); Table 3. Again, the Y-chromosome showed slightly higher values of among-population variance than did the mtDNA. For the Y-chromosome, a significant proportion of the within- population variance moved to among-population within-groups variance, probably due to the fact that all population samples had a very high proportion of singleton Yfiler haplotypes, elevating the maximum values of haplogroup diversity for all of them [33].

\section{Linguistic isolates: Ladin and Grecani Salentini}

Two linguistic isolates are represented in the samples analyzed in the present study: the Ladin and the Grecani Salentini.

Other population samples of the Ladin have already been analyzed in the literature $[22,62,63]$. We here sampled 41 new

Table 3. AMOVA analysis of main Italian regions (Permutations: 20000 ; $P$-value $<0.0000$ ) for the mtDNA control region data and the Y-chromosome STRs and SNPs.

\begin{tabular}{|c|c|c|c|}
\hline & All populations (\%) & $\begin{array}{l}\text { North vs Center vs South } \\
(\%)\end{array}$ & West vs East (\%) \\
\hline \multicolumn{4}{|l|}{ HAPLOTYPES } \\
\hline \multicolumn{4}{|l|}{ mtDNA (48 populations) } \\
\hline Among pops & 0.79 & 0 & 0 \\
\hline Within pops & 99.21 & 99.25 & 99.21 \\
\hline Among pops within groups & - & 0.75 & 0.79 \\
\hline \multicolumn{4}{|c|}{ Y-chromosome (15 populations) } \\
\hline Among pops & 2.34 & 1.18 & 0 \\
\hline Within pops & 97.66 & 97.32 & 97.85 \\
\hline Among pops within groups & - & 1.50 & 2.15 \\
\hline \multicolumn{4}{|l|}{ HAPLOGROUPS } \\
\hline \multicolumn{4}{|l|}{ mtDNA (19 populations) } \\
\hline Among pops & 1.17 & 0.36 & 0 \\
\hline Within pops & 98.83 & 98.72 & 98.83 \\
\hline Among pops within groups & - & 0.92 & 1.17 \\
\hline \multicolumn{4}{|c|}{ Y-chromosome (24 populations) } \\
\hline Among pops & 13.92 & 0.07 & 0.83 \\
\hline Within pops & 86.08 & 86.06 & 85.74 \\
\hline Among pops within groups & - & 13.87 & 13.44 \\
\hline
\end{tabular}

Sardinians were not included in the analysis. References for population samples are given in Table S2.

doi:10.1371/journal.pone.0050794.t003 
individuals from the locality of Val Badia. As reported in Table 4 for the mtDNA, Val Badia Ladins showed relatively high nucleotide diversity patterns compared to other Ladin populations, but intermediate haplotype diversity values. Compared to other Italian populations, diversity in Ladin populations is generally lower (Table 1). For Y-chromosome haplogroups, the differences between Ladin and the rest of Italy were more evident, with the Ladin showing much lower values than average Italians.

The differences between Ladin and other populations were more evident when examining haplogroup frequency patterns (Figure 4). The frequency of haplogroup $\mathrm{H}(58 \%)$ was above the frequency of $\mathrm{H}$ in North Italy $(55 \%)$, and was extremely high $(58 \%)$ compared to the average for Italy (38\%) (Pearson's Chisquare test, $P$-value $=0.0005)$. While haplogroup $\mathrm{U}$ was found to have approximately the same frequency as other Italian populations, haplogroup $\mathrm{T}$ was $5 \%$ compared to $12 \%$ in Italy generally (7\% in the North). Other differences were apparent, but sample sizes were relatively low to yield significant statistical differences.

Differences are more important when examining Y-chromosome haplogroup frequencies. R1b3 reached $52 \%$ in Ladin populations but only $31 \%$ in the general population, and also in the North (Pearson's Chi-square test, $P$-value $=0.0087$ ); Figure 4 . More remarkable are the differences when considering the remaining $\mathrm{R} 1 \mathrm{~b}$ lineages, that is, $\mathrm{R} 1 \mathrm{~b}(\mathrm{xR} 1 \mathrm{~b} 3)$, which account for $15 \%$ of the lineages in Ladins, but only for $1 \%$ in the general population (Pearson's Chi-square test, $P$-value $=0.0001$ ). Other haplogroups showed substantial haplogroup differences (e.g. J2) but the sample size was again too small.

Due to the availability of data for mtDNA in several Ladin communities, we were able to carry out an AMOVA analysis in order to investigate the level of population stratification in these communities. The data indicated that among-population variance is $1.09 \%$, a value that is therefore higher than the average for the Italian Peninsula $(0.79 \%$; Table 4).

Some interesting features were also found for Ladin populations when examined at the haplotype level. For instance, the HVS-I profile G16129A C16192T A16270G T16304C was found in four Ladins from Val Badía; this profile belongs to haplogroup U5b3f [20]. In a large in-house database of worldwide profiles $(>130,000$ HVS-I segments), this sequence was only found sporadically in other Italian regions and in Spain (Catalonia, Galicia, and Ibiza in the Balearic Islands). U5b3f is a minor clade of U5b3, the only haplogroup reported to date that has been found to represent the glacial refuge zone in Northern Italy and a source population for human re-colonization of the continent at the beginning of the Holocene. The study of Pala et al. [20] indicates that this lineage mainly expanded along the Mediterranean coast towards the Iberian Peninsula; one sub-clade also reached Sardinia 7000-9000 years ago. The branch observed in the Ladins is younger and could also have participated in the Mediterranean spread of U5b3f towards Iberia, given its presence in modern-day Spain. The data suggest that the U5b3f members observed in the Ladins probably predate the Ladin ethnogenesis and, given that this population has somehow become isolated from other neighboring populations, could reach a substantial frequency in some other Ladin communities, as is the case for the Val Badia. Another example is the U3 profile A16233G C16256T T16311G A16343G, which was only found in five Ladins from Alto Adige (Val Badia and Val Gardena), while T16352C C16354T was found in six individuals from Val Badia in South Tyrol.

Diversity values in the Grecani Salentini samples were similar to those observed in other Italian regions. Moreover, they also show haplogroup frequency patters in the Y-chromosome and the mtDNA that matches well with other Italian samples. The haplogroups are typically European (Figure 4); given the southern location of the Grecani Salentini in the Italian Peninsula, it is noticeable that there is no evidence of North African lineages. Note however, that at higher level of phylogenetic resolution, there are signals on the Y-chromosome of North African enrichment in South Italy [31].

\section{The North African historical legacy in South Italy}

We sampled 60 individuals from Lucera. This population sample showed diversity values that fell within the average of a typical Italian population, regarding the mtDNA (Table 1) and the Y-chromosome (Table 2). Additionally, at the level of haplogroup frequencies, Lucera matched well with other Italian populations (Figure 4).

There are two mtDNA haplogroups, namely U6 and M1 that can be considered to be of North African origin and could therefore be used to signal the documented historical input of this African region into Lucera. In our full set of samples, we observed five U6 haplotypes belonging to sub-haplogroups U6a, U6a2, and U6a4. Only one of these haplotypes was observed in Lucera. However, the other three U6 haplotypes were observed in the vicinity of the population of South Apulia, and another at the tip of the Peninsula (Calabria). Regarding M1 haplotypes, we observed only two carriers in our samples sharing the same HVS-I haplotype; both were found in Trapani (West Sicily).

Therefore, while South Italy shows evidence of having female introgression from North Africa, this African influence seems not to be particularly centered in the Lucera. In the Y-chromosome, we did not observe any signal of North African introgression; at least, no more than for other regions of Italy (perhaps with the exception of Sicily [31]). This again contrasts with the results of previous studies based on the Y-chromosome (but at higher or different level of phylogenetic resolution involving the genotyping of African minor sub-lineages) where signals of North African influence were observed at this latitude of the Peninsula [31].

\section{Discussion}

A meta-analysis of Y-chromosome and mtDNA sequence data was undertaken in order to investigate patterns of genetic variation

Table 4. Mitochondrial DNA molecular diversity values of different Ladin populations.

\begin{tabular}{|c|c|c|c|c|c|c|c|c|}
\hline Ladin populations & References & $N$ & $k$ & $k / n$ & $s$ & $h$ & $\Pi$ & $M$ \\
\hline Val Badia & p.s, [22] & 97 & 55 & 0.6 & 60 & $0.958 \pm 0.012$ & $0.01206 \pm 0.0008$ & 4.101 \\
\hline Val Gardena & {$[22,66]$} & 56 & 27 & 0.5 & 42 & $0.906 \pm 0.027$ & $0.01216 \pm 0.0011$ & 4.158 \\
\hline Colle S. Lucia & {$[62,66]$} & 30 & 17 & 0.8 & 33 & $0.947 \pm 0.022$ & $0.01885 \pm 0.0010$ & 6.448 \\
\hline Val di Fassa & 67 & 47 & 25 & 0.5 & 34 & $0.932 \pm 0.026$ & $0.01242 \pm 0.0012$ & 4.135 \\
\hline
\end{tabular}




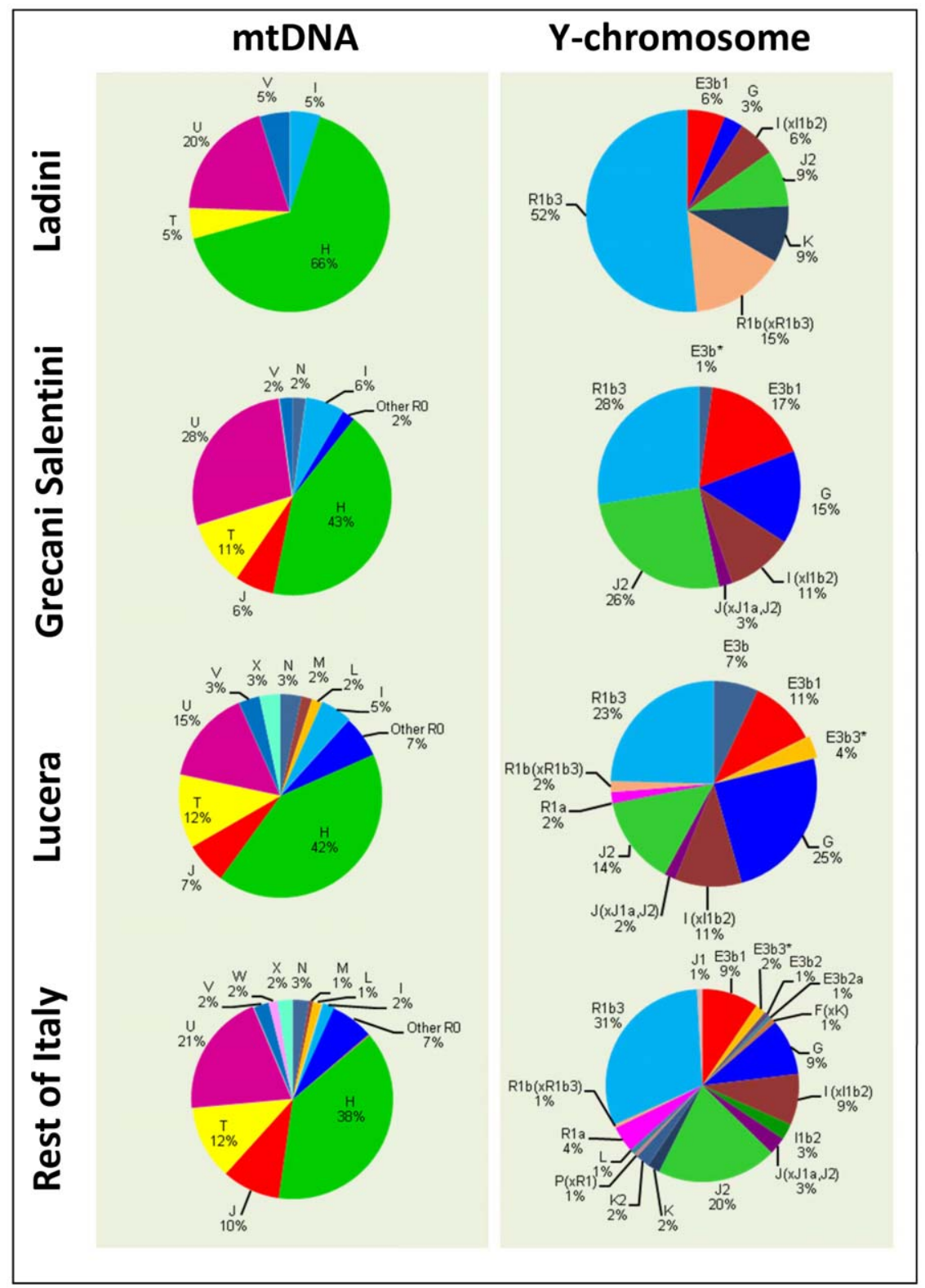

Figure 4. Haplogroup frequencies of Ladins, Grecani Salentini and Lucera compared to the rest of the Italian populations analyzed in the present study.

doi:10.1371/journal.pone.0050794.g004

throughout Italy. Molecular indices indicated that most of the Italian samples show diversity values that are comparable to other European populations. However, some differences were shown to exist, especially in isolated Ladin populations. Regional differences were much more evident when examining haplogroup frequencies in both uniparental markers. The differences were again more remarkable for the two linguistic isolates, the Ladins and Grecani Salentini. AMOVA also indicated the existence of significant population stratification along the length of the country, which appeared more remarkable for the Y-chromosome and for haplogroups than for haplotypes. These figures have however to be considered with caution given the different mutability of the markers being analyzed [64]; see also a discussion in [65].

Over the last few years, the interest in genetically isolated populations has increased, especially in biomedical studies, where there exists a growing interest in revealing genetic variants associated to disease. Genetic isolates generally originate as a result of group "foundation" by a small number of individuals presenting initially low variability. We have here analyzed a new sample of the Ladins, a well-known linguistic and genetic isolate from the Italian Alps. Some investigations were focused on the Ladin Romance speaking populations, distributed between Trentino, the Veneto regions and South Tyrol area $[22,62,63,66]$. As also observed in the present study, Ladin communities show marked genetic differentiation with neighboring (non-Ladin) populations. Differences were also observed between the different Ladin groups; for instance, AMOVA analysis also indicated that the different Ladin communities show a level of population stratification that is higher than the average in the rest of Italy. These results are also consistent with the recent study by Coia et al. [67], derived from micro-geographical analysis of nine sample populations from Trentino (Eastern Italian Alps). 
Genetic differences between Ladin samples are most likely to be due to the limited historical gene flow existing between these communities [22]. In this regard, it is also noticeable that, while the South Tyrol populations show clear signatures of isolation, the Veneto groups presented a high degree of genetic variability [68].

The Grecani Salentini also showed signatures of genetic isolation when compared to other Italian populations, but the differences are not as marked as observed for the Ladins. The differences with respect to neighboring Italian populations were not evident when observing individual haplotypes (as occurs with the Ladins), but were clearer when considering haplogroup frequencies (Figure 4). Larger sample sizes are needed in order to gather more signatures about the demographic past of this population. Thus, the Ladins show a more distinctive pattern than the Grecani Salentini, which is to be expected given that not only is the Ladin population a linguistic isolate, but also that these communities are confined to isolated geographical areas of the Alps.

Apart from the regional and local genetic differences observed in Italy, it is also worth examining global genetic patterns along the length of continental Italy.

Geographical clines of Y-chromosome haplogroups in Europe have been previously reported in the literature [13]; these patterns have found support in archaeological and linguistic evidence. In the Italian peninsula, the Y-chromosome variation also shows a clinal pattern along the North-South axis; the Mesolithic haplogroup R1*(xRlal) shows higher frequency in the North while the Neolithic haplogroup J2-M172 is superposed to this Mesolithic strata with frequency patterns running in the opposite direction [14,69]. The results of the present study agreed with these earlier findings. Thus, for instance, R1b3 reached 31\% in the North, 16\% in the Center, and 14\% in the South. Frequency of Y-chromosome haplogroup J2 was found to be $9 \%$ in the North, $37 \%$ in the Center, and $22 \%$ in the South (average in Italy: $14.5 \%$ ). Haplogroup J2 is widely believed to be associated with the spread of agriculture from Mesopotamia. The main spread of J2 into the Mediterranean area is thought to have coincided with the expansion of agricultural populations during the Neolithic period. As reported by Di Giacomo et al. [12], haplogroup J “...constitutes not only the signature of a single wave-of-advance from the Levant but, to a greater extent, also of the expansion of the Greek world, with an accompanying novel quota of genetic variation produced during its demographic growth..."; also that "...in the central and west Mediterranean, the entry of $\mathcal{f}$ chromosomes may have occurred mainly by sea, i.e., in the south-east of both Spain and Italy...". J2-M12 is almost totally represented by its sublineage J2-M102, which shows frequency peaks in both the southern Balkans and north-central Italy (14\%; [13]). J2-M67 is most frequent in the Caucasus, and J2-M92 indicates affinity between Anatolia and southern Italy (21.6\%; [13]). For the J1M170 clade, the peaks of J1-M267 are in the Levant and in northern Africa, and it is closely associated to the diffusion of the Arab people, dropping abruptly outside of this area (including Anatolia and the Iberian peninsula), even if it shows an appreciable percentage in Sicily [70]. In a recent study, Pala et al. [71] confirmed that mtDNA haplogroups $\mathrm{J}$ and $\mathrm{T}$ and their major sub-clades (J1 and J2, T1 and T2) most likely arose in the Near East at the time of the first settlement by modern humans and the LGM. These haplogroups started to spread from the Near East into Europe immediately after the peak of the last glaciation, about 19 kya ago, with a major expansions in Europe in the Late Glacial period, about 16-12 kya ago, thus indicating that many of the Neolithic expansions from southern Europe into Central Europe and the Mediterranean might have been indigenous dispersal of these lineages.
Latitudinal clinal frequency patterns are also observed for the mtDNA haplogroups mirroring those of the Y-chromosome. As reported by Richards et al. [38], haplogroups $\mathrm{H}, \mathrm{K}, \mathrm{T} *, \mathrm{~T} 2, \mathrm{~W}$, and $\mathrm{X}$ are the major contributors to the Late Upper Paleolithic, and the central-Mediterranean region has the greatest Middle Upper Paleolithic component outside the Caucasus. In agreement with the Y-chromosome, we observed that all these Paleolithic haplogroups together add to approximately $70.3 \%$ in the North, $60.8 \%$ in the Center, and $54 \%$ in the South of Italy. The opposite pattern was observed for the main mtDNA Neolithic component, represented by haplogroups $\mathrm{J}$ and $\mathrm{T} 1$, which accounted for $5.8 \%$ in the North, $10.3 \%$ in the Center, and $14.1 \%$ in the South (Italian average: $10.5 \%$ ).

As early as 1934, [72], Vere Gordon Childe suggested that the indigenous communities of hunters and gatherers of the Mesolithic European cultures were replaced by communities of farmers migrating to the North from the Middle East, a process that lasted for several generations. The first stream of emigration followed the route along the continental Balkan Peninsula and the Danube, while another, slightly later, emigration spread along the coasts of the Mediterranean Sea from East to West. The latter path would fit well with the distribution of other Neolithic cultural features, such as the so-called Cardium Pottery (or Cardial Ware) [73], the ceramic decorative style that better defines the Neolithic culture. This culture entered from Greece towards the South-Center of Italy through the Adriatic Sea, carried by the same farmers that introduced, for instance, Y-chromosome haplogroup J2 at about the same frequency in Central and South Italy, but with lower introgression into the North; from here followed further Mediterranean expansions towards Iberia.

The sub-clade E3bl (probably originating in eastern Africa) has a wide distribution in sub-Saharan Africa, Middle East and Europe. This haplogroup reaches a frequency of $8 \%$ in the North and Center and slightly higher in the South of Italy, 11\% (Figure 1). It has also been argued that the European distribution of E3bl is compatible with the Neolithic demic diffusion of agriculture [15]; thus, two sub-clades, E3bla- M78 and E3blcM123 present a higher occurrence in Anatolia, the Balkans and the Italian peninsula. Another sub-clade, E3blb-M81 is associated with the Berber populations and is commonly found in regions that have had historical gene flow with Northern Africa, such as the Iberian peninsula [74,75]-[76-78], including the Canary Islands [75], and Sicily [70,79]; the absence of microsatellite variation suggests a very recent arrival from North Africa [80]. If we assume that all E3bl represents the only Y-chromosome continental African contribution to Italy and L and U6 lineages the continental African mtDNA component, the African component in Italy is higher for the Y-chromosome (8-11\%) than for mtDNA $(1-2 \%)$. The origin of sub-Saharan African mtDNAs in Europe (including Italian samples) has been recently investigated by Cerezo et al. [81]; the results indicate that a significant proportion of these lineages could have arrived in Italy more than 10,000 years ago; therefore, their presence in Europe does not necessarily date to the time of the Roman Empire, the Atlantic slave trade or to modern migration.

In addition, the Northern African influence in the Italian Peninsula is evidenced by the presence of Northern African Y chromosome haplogroups (E1-M78) in three geographically close samples across the southern Apennine mountains: East Campania, Northwest Apulia and Lucera [31]. The Lucera sample analyzed in the present study did not however show a higher impact from North Africa than for other areas from southern Italy [31].

Finally, in agreement with uniparental markers, analysis of AIMs as carried out in the present study indicated that Italy shows 
a very minor sub-Saharan African component that is, however, slightly higher than non-Mediterranean Europe. This agrees with the recent findings of Cerezo et al. [82] based on the analysis of entire mtDNA genomes pointing to the arrival in ancient and historical times of sub-Saharan African people to the Mediterranean Europe, followed by admixture.

The present study represents the largest meta-analysis carried out to date for the Italian peninsula. We observed that the Ychromosome and the mtDNA retain the imprint of the major ancestral events occurring in Italy; however, the Y-chromosome shows more marker regional differences than does the mtDNA. It is difficult to infer what proportion of these differences can be attributed not only exclusively to gender demographic differences, but also to the fact that both markers were analyzed to different levels of molecular resolution. Italy shows clines of variation attributable to the demographic movements of the first Paleolithic settlements, posteriorly modeled by the Mesolithic and, to a lesser extent, Neolithic farmers. Regional differences arose with time, which are more notable in linguistic isolates, such as the Ladin populations, and to a minor extent, the Grecani Salentini. Lot of effort has been dedicated during the last two decades to the study of Italian populations. Further studies are needed in order to dig into some of the many demographic movements occurring in the Italian peninsula along history. Entire genome sequencing of particular lineages (in the line of e.g. [20]) and nuclear DNA genomic studies are needed in order to explore hypothesis beyond what has been done to date in Italy.

\section{References}

1. Cunliffe B (2001) The Oxford Illustrated History of Prehistoric Europe: Oxford University Press.

2. Guidi A, Piperno M (2005) Italia preistorica. Roma: Laterza.

3. Abulafia D (2001) The Great Sea: A human history of the Mediterranean Oxford University Press.

4. Buti GG (1974) Preistoria e storia delle regioni d'Italia: Sansoni Università.

5. Devoto G (1977) Gli antichi italici: Firenze, Vallecchi.

6. Pallottino M (1981) Genti e culture dell'Italia preromana. Jouvence: 136.

7. Stenico M, Nigro L, Barbujani G (1998) Mitochondrial lineages in Ladinspeaking communities of the eastern Alps. Proc R Soc Lond B 265: 555-561.

8. Achilli A, Olivieri A, Pala M, Metspalu E, Fornarino S, et al. (2007) Mitochondrial DNA variation of modern Tuscans supports the near eastern origin of Etruscans. Am J Hum Genet 80: 759-768.

9. Brisighelli F, Capelli C, Álvarez-Iglesias V, Onofri V, Paoli G, et al. (2009) The Etruscan timeline: A recent Anatolian connection. Eur J Hum Genet 17: 693696.

10. Francalacci P, Bertranpetit J, Calafell F, Underhill PA (1996) Sequence diversity of the control region of mitochondrial DNA in Tuscany and its implications for the peopling of Europe. Am J Phys Anthropol 100: 443-460.

11. Onofri V, Alessandrini F, Turchi C, Fraternale B, Buscemi L, et al. (2007) Ychromosome genetic structure in sub-Apennine populations of Central Italy by SNP and STR analysis. Int J Legal Med 121: 234-237.

12. Di Giacomo F, Luca F, Anagnou N, Ciavarella G, Corbo RM, et al. (2003) Clinal patterns of human $\mathrm{Y}$ chromosomal diversity in continental Italy and Greece are dominated by drift and founder effects. Mol Phylogenet Evol 28: 387-395.

13. Semino O, Passarino G, Oefner PJ, Lin AA, Arbuzova S, et al. (2000) The genetic legacy of Paleolithic Homo sapiens sapiens in extant Europeans: A Y chromosome perspective. Science 290: 1155-1159.

14. Capelli G, Brisighelli F, Scarnicci F, Arredi B, Caglia A, et al. (2007) Y chromosome genetic variation in the Italian peninsula is clinal and supports an admixture model for the Mesolithic-Neolithic encounter. Mol Phylogenet Evol 44: $228-239$.

15. Semino O, Magri C, Benuzzi G, Lin AA, Al-Zahery N, et al. (2004) Origin, diffusion, and differentiation of Y-chromosome haplogroups $\mathrm{E}$ and $\mathrm{J}$ : Inferences on the neolithization of Europe and later migratory events in the Mediterranean area. Am J Hum Genet 74: 1023-1034.

16. Trombetta B, Cruciani F, Sellitto D, Scozzari R (2011) A new topology of the human Y chromosome haplogroup E1b1 (E-P2) revealed through the use of newly characterized binary polymorphisms. PLoS ONE 6: e16073.

17. Francalacci P, Sanna D (2008) History and geography of human Y-chromosome in Europe: A SNP perspective. J Anthropol Sci 86: 59-89.

\section{Supporting Information}

Table S1 mtSNPs and primers used to characterize J/T and $U$ and some of their sub-clades.

(XLS)

Table S2 References to the population samples used in the present study for population comparison analysis.

(XLS)

Table S3 Mitochondrial DNA control region haplotypes obtained from the samples analyzed in the present study.

(XLS)

Table S4 Y-SNP and Y-STR profiles of the Italian samples analyzed in the present study. Note that the $\mathrm{Y}$ STR data has already been reported in Brisighelli et al. [65]. (XLS)

\section{Acknowledgments}

We would like to thank two anonymous reviewers for their very useful comments on the present study.

\section{Author Contributions}

Conceived and designed the experiments: FB CG AS. Performed the experiments: FB VAI MF ABV. Analyzed the data: FB AS. Contributed reagents/materials/analysis tools: AC VLP AS. Wrote the paper: FB AS. Gritically revised the paper and made suggestions on a first draft: CG. Approved the final version of the manuscript: FB VAI MF ABV AC VLP AS.

18. Di Gaetano C, Cerutti N, Crobu F, Robino C, Inturri S, et al. (2009) Differential Greek and northern African migrations to Sicily are supported by genetic evidence from the Y chromosome. Eur J Hum Genet 17: 91-99.

19. Brigaglia M (1989) Storia della Sardegna. Edizioni Della Torre.

20. Pala M, Achilli A, Olivieri A, Kashani BH, Perego UA, et al. (2009) Mitochondrial haplogroup U5b3: A distant echo of the epipaleolithic in Italy and the legacy of the early Sardinians. Am J Hum Genet 84: 814-821.

21. Montanini L, Regna-Gladin C, Eoli M, Albarosa R, Carrara F, et al. (2005) Instability of mitochondrial DNA and MRI and clinical correlations in malignant gliomas. J Neurooncol 74: 87-89.

22. Thomas MG, Barnes I, Weale ME, Jones AL, Forster P, et al. (2008) New genetic evidence supports isolation and drift in the Ladin communities of the South Tyrolean Alps but not an ancient origin in the Middle East. Eur J Hum Genet 16: 124-134.

23. Achilli A, Rengo C, Magri C, Battaglia V, Olivieri A, et al. (2004) The molecular dissection of mtDNA haplogroup $\mathrm{H}$ confirms that the Franco-Cantabrian glacial refuge was a major source for the European gene pool. Am J Hum Genet 75: 910-918.

24. Torroni A, Bandelt H-J, Macaulay V, Richards M, Cruciani F, et al. (2001) A signal, from human mtDNA, of postglacial recolonization in Europe. Am J Hum Genet 69: 844-852.

25. Álvarez-Iglesias V, Mosquera-Miguel A, Cerezo M, Quintáns B, Zarrabeitia MT, et al. (2009) New population and phylogenetic features of the internal variation within mitochondrial DNA macro-haplogroup R0. PLoS One 4: e5112.

26. Gómez-Carballa A, Olivieri A, Behar DM, Achilli A, Torroni A, et al. (2012) Genetic continuity in the Franco-Cantabrian region: New clues from autochthonous mitogenomes. PLoS ONE 7: e32851.

27. De Concini W (2003) Gli altri d'Italia: minoranze linguistiche allo specchio Pergine Valsugana (TN).

28. Castagnetti A (2004) Storia del Trentino. (L'età Medievale). 3 Vol, Bologna, Il Mulino, 2000-2005.

29. De Concini W (1997) Gli altri delle Alpi. Minoranze linguistiche dell'arco alpino italiano. Trento, Grafiche Artigianelli.

30. Carducci L (1993) Storia del Salento. La terra de'Otranto dale origini ai primi del cinquecento. Galatina: Congedo.

31. Capelli C, Onofri V, Brisighelli F, Boschi I, Scarnicci F, et al. (2009) Moors and Saracens in Europe: Estimating the medieval North African male legacy in southern Europe. Eur J Hum Genet 17: 848-852.

32. Norman D (1975) The Arabs and Medieval Europe. London, UK Longmann Group Limited. 
33. Brisighelli F, Blanco-Verea A, Boschi I, Garagnani P, Pascali VL, et al. (2011) Global patterns of Y-STR variation in Italy. Forensic Sci Int Genet in press; 10.1016/j.fsigen.2012.03.003

34. Miller SA, Dykes DD, Polesky HF (1988) A simple salting out procedure for extracting DNA from human nucleated cells. Nucleic Acids Res 16: 1215.

35. Álvarez-Iglesias V, Jaime JC, Carracedo Á, Salas A (2007) Coding region mitochondrial DNA SNPs: targeting East Asian and Native American haplogroups. Forensic Sci Int Genet 1: 44-55.

36. Anderson S, Bankier AT, Barrell BG, de Bruijn MHL, Coulson AR, et al. (1981) Sequence and organization of the human mitochondrial genome. Nature 290: $457-465$.

37. Quintáns B, Álvarez-Iglesias V, Salas A, Phillips C, Lareu MV, et al. (2004) Typing of mitochondrial DNA coding region SNPs of forensic and anthropological interest using SNaPshot minisequencing. Forensic Sci Int 140: 251-257.

38. Richards M, Macaulay V, Hickey E, Vega E, Sykes B, et al. (2000) Tracing European founder lineages in the Near Eastern mtDNA pool. Am J Hum Genet 67: 1251-1276.

39. Brión M, Sobrino B, Blanco-Verea A, Lareu MV, Carracedo Á (2005) Hierarchical analysis of $30 \mathrm{Y}$-chromosome SNPs in European populations. Int J Legal Med 119: 10-15.

40. YCC (2002) A nomenclature system for the tree of human Y-chromosomal binary haplogroups. Genome Res 12: 339-348.

41. Sánchez JJ, Phillips C, Børsting C, Balogh K, Bogus M, et al. (2006) A multiplex assay with 52 single nucleotide polymorphisms for human identification. Electrophoresis 27: 13-24.

42. Amigo J, Salas A, Phillips C (2011) ENGINES: exploring single nucleotide variation in entire human genomes. BMC Bioinformatics 12: 105.

43. Amigo J, Salas A, Phillips C, Carracedo Á (2008) SPSmart: adapting population based SNP genotype databases for fast and comprehensive web access. BMC Bioinformatics 9: 428.

44. Nei N (1987) Molecular evolutionary genetics: New York: Columbia University Press.

45. Tajima F (1983) Evolutionary relationship of DNA sequences in finite populations. Genetics 105: 437-460.

46. Tajima F (1993) Unbiased estimation of evolutionary distance between nucleotide sequences. Mol Biol Evol 10: 677-688.

47. Rozas J, Sanchez-DelBarrio JC, Messeguer X, Rozas R (2003) DnaSP, DNA polymorphism analyses by the coalescent and other methods. Bioinformatics 19: 2496-2497.

48. Excoffier L, Lischer HEL (2010) Arlequin suite ver 3.5: A new series of programs to perform population genetics analyses under Linux and Windows. Mol Ecol Res 10: 564-567.

49. Loogväli E-L, Roostalu U, Malyarchuk BA, Derenko MV, Kivisild T, et al. (2004) Disuniting uniformity: A pied cladistic canvas of mtDNA haplogroup $\mathrm{H}$ in Eurasia. Mol Biol Evol 21: 2012-2021.

50. Macaulay V, Richards M, Hickey E, Vega E, Cruciani F, et al. (1999) The emerging tree of West Eurasian mtDNAs: a synthesis of control-region sequences and RFLPs. Am J Hum Genet 64: 232-249.

51. van Oven M, Kayser M (2009) Updated comprehensive phylogenetic tree of global human mitochondrial DNA variation. Hum Mutat 30: E386-394.

52. Salas A, Yao Y-G, Macaulay V, Vega A, Carracedo A, et al. (2005) A critical reassessment of the role of mitochondria in tumorigenesis. PLoS Med 2: e296.

53. Salas A, Prieto L, Montesino M, Albarrán C, Arroyo E, et al. (2005) Mitochondrial DNA error prophylaxis: Assessing the causes of errors in the GEP'02-03 proficiency testing trial. Forensic Sci Int 148: 191-198.

54. Salas A, Carracedo Á, Macaulay V, Richards M, Bandelt H-J (2005) A practical guide to mitochondrial DNA error prevention in clinical, forensic, and population genetics. Biochem Biophys Res Commun 335: 891-899.

55. Salas A, Bandelt H-J, Macaulay V, Richards MB (2007) Phylogeographic investigations: The role of trees in forensic genetics. Forensic Sci Int 168: 1-13.

56. Yao Y-G, Salas A, Logan I, Bandelt H-J (2009) mtDNA data mining in GenBank needs surveying. Am J Hum Genet 85: 929-933; author reply 933.

57. Bandelt H-J, Salas A, Lutz-Bonengel S (2004) Artificial recombination in forensic mtDNA population databases. Int J Legal Med 118: 267-273.

58. Bandelt H-J, Salas A, Bravi CM (2004) Problems in FBI mtDNA database. Science 305: 1402-1404

59. Bandelt H-J, Quintana-Murci L, Salas A, Macaulay V (2002) The fingerprint of phantom mutations in mitochondrial DNA data. Am J Hum Genet 71: 11501160.

60. Olivieri A, Achilli A, Pala M, Battaglia V, Fornarino S, et al. (2006) The mtDNA legacy of the Levantine early Upper Palaeolithic in Africa. Science 314: 17671770 .

61. Salas A, Richards M, De la Fé T, Lareu MV, Sobrino B, et al. (2002) The making of the African mtDNA landscape. Am J Hum Genet 71: 1082-1111.

62. Vernesi C, Fuselli S, Castri L, Bertorelle G, Barbujani G (2002) Mitochondrial diversity in linguistic isolates of the Alps: A reappraisal. Hum Biol 74: 725-730.

63. Pichler I, Mueller JC, Stefanov SA, De Grandi A, Beu Volpato C, et al. (2006) Genetic structure in contemporary South Tyrolean isolated populations revealed by analysis of Y-Chromosome, mtDNA, and Alu polymorphisms. Hum Biol 78: $441-464$.

64. Meirmans PG, Hedrick PW (2011) Assessing population structure: F(ST) and related measures. Mol Ecol Resour 11: 5-18.

65. Brisighelli F, Blanco-Verea A, Boschi I, Garagnani P, Pascali VL, et al. (2012) Patterns of Y-STR variation in Italy. Forensic Sci Int Genet in press.
66. Stenico M, Nigro L, Bertorelle G, Calafell F, Capitanio M, et al. (1996) High Mitochondrial Sequence Diversity in Linguistic Isolates of the Alps. Am J Hum Genet 59: 1363-1375.

67. Coia V, Boschi I, Trombetta F, Cavulli F, Montinaro F, et al. (2012) Evidence of high genetic variation among linguistically diverse populations on a microgeographic scale: a case study of the Italian Alps. J Hum Genet 57: 254-260.

68. Destro Bisol G, Anagnostou P, Batini C, Battaggia C, Bertoncini S, et al. (2008) Italian isolates today: geographic and linguistic factors shaping human biodiversity. J Anthropol Sci 86: 179-188.

69. Busby GB, Brisighelli F, Sánchez-Diz P, Ramos-Luis E, Martinez-Cadenas C, et al. (2012) The peopling of Europe and the cautionary tale of $\mathrm{Y}$ chromosome lineage R-M269. Proc Biol Sci 279: 884-892.

70. Semino O, Magri C, Benuzzi G, Lin AA, Al-Zahery N, et al. (2004) Origin, diffusion, and differentiation of Y-chromosome haplogroups $\mathrm{E}$ and $\mathrm{J}$ : Inferences on the neolithization of Europe and later migratory events in the Mediterranean area. Am J Hum Genet 74: 1023-1034.

71. Pala M, Olivieri A, Achilli A, Accetturo M, Metspalu E, et al. (2012) Mitochondrial DNA signals of late glacial recolonization of Europe from near eastern refugia. Am J Hum Genet 90: 915-924.

72. Childe VG (1934) New light on the most ancient East: The oriental Prelude to European prehistory: London: K Paul, Trench, Trubner \& Co.

73. King R, Underhill $\mathrm{P}$ (2002) Congruent distribu- tion of Neolithic painted pottery and ceramic figurines with Y-chromosome lineages. Antiquity 76: 707-714.

74. Maca-Meyer N, Sanchez-Velasco P, Flores C, Larruga JM, Gonzalez AM, et al (2003) Y chromosome and mitochondrial DNA characterization of Pasiegos, a human isolate from Cantabria (Spain). Ann Hum Genet 67: 329-339.

75. Flores C, Maca-Meyer N, Perez JA, Gonzalez AM, Larruga JM, et al. (2003) A predominant European ancestry of paternal lineages from Canary Islanders. Ann Hum Genet 67: 138-152.

76. Goncalves R, Freitas A, Branco M, Rosa A, Fernandes AT, et al. (2005) Ychromosome lineages from Portugal, Madeira and Acores record elements of Sephardim and Berber ancestry. Ann Hum Genet 69: 443-454.

77. Alonso S, Flores C, Cabrera V, Alonso A, Martin P, et al. (2005) The place of the Basques in the European Y-chromosome diversity landscape. Eur J Hum Genet 13: 1293-1302.

78. Beleza S, Gusmão L, Lopes A, Alves C, Gomes I, et al. (2006) Microphylogeographic and demographic history of Portuguese male lineages. Ann Hum Genet 70: 181-194.

79. Cruciani F, La Fratta R, Santolamazza P, Sellitto D, Pascone R, et al. (2004) Phylogeographic analysis of haplogroup E3b (E-M215) y chromosomes reveals multiple migratory events within and out of Africa. Am J Hum Genet 74: 1014 1022 .

80. Bosch E, Calafell F, Comas D, Oefner PJ, Underhill PA, et al. (2001) Highresolution analysis of human Y-chromosome variation shows a sharp discontinuity and limited gene flow between northwestern Africa and the Iberian Peninsula. Am J Hum Genet 68: 1019-1029.

81. Cerezo M, Achilli A, Olivieri A, Perego UA, Gómez-Carballa A, et al. (2012) Reconstructing ancient mitochondrial DNA links between Africa and Europe. Genome Res in press.

82. Cerezo M, Achilli A, Olivieri A, Perego UA, Gómez-Carballa A, et al. (2012) Reconstructing ancient mitochondrial DNA links between Africa and Europe. Genome Res 22: 821-826.

83. Amigo J, Phillips C, Salas A, Carracedo A (2009) Viability of in-house datamarting approaches for population genetics analysis of SNP genotypes. BMC Bioinformatics 10: S5.

84. Turchi C, Buscemi L, Giacchino E, Onofri V, Fendt L, et al. (2009) Polymorphisms of mtDNA control region in Tunisian and Moroccan populations: An enrichment of forensic mtDNA databases with Northern Africa data. Forensic Sci Int Genet 3: 166-172.

85. Messina F, Scorrano G, Labarga CM, Rolfo MF, Rickards O Mitochondrial DNA variation in an isolated area of Central Italy. Ann Hum Biol 37: 385-402.

86. Babalini C, Martínez-Labarga C, Tolk HV, Kivisild T, Giampaolo R, et al (2005) The population history of the Croatian linguistic minority of Molise (southern Italy): A maternal view. Eur J Hum Genet 13: 902-912.

87. Falchi A, Giovannoni L, Calo CM, Piras IS, Moral P, et al. (2006) Genetic history of some western Mediterranean human isolates through mtDNA HVR1 polymorphisms. J Hum Genet 51: 9-14.

88. Verginelli F, Donati F, Coia V, Boschi I, Palmirotta R, et al. (2003) Variation of the hypervariable region-1 of mitochondrial DNA in central-eastern Italy. J Forensic Sci 48: 443-444.

89. Bini C, Ceccardi S, Luiselli D, Ferri G, Pelotti S, et al. (2003) Different informativeness of the three hypervariable mitochondrial DNA regions in the population of Bologna (Italy). Forensic Sci Int 135: 48-52.

90. Tagliabracci C, Turchi C, Buscemi L, Sassaroli C (2001) Polymorphism of the mitochondrial DNA control region in Italians. Int J Legal Med 114: 224-228.

91. Ottoni C, Martinez-Labarga C, Vitelli L, Scano G, Fabrini E, et al. (2009) Human mitochondrial DNA variation in Southern Italy. Ann Hum Biol 36: 785-811.

92. Rose G, Longo T, Maletta R, Passarino G, Bruni AC, et al. (2008) No evidence of association between frontotemporal dementia and major European mtDNA haplogroups. Eur J Neurol 15: 1006-1008.

93. Ottoni C, Martinez-Labarga C, Loogvali EL, Pennarun E, Achilli A, et al. (2009) First genetic insight into Libyan Tuaregs: a maternal perspective. Ann Hum Genet 73: 438-448. 
94. Cali F, Le Roux MG, D'Anna R, Flugy A, De Leo G, et al. (2001) MtDNA control region and RFLP data for Sicily and France. Int J Legal Med 114: 229231.

95. Forster P, Cali F, Rohl A, Metspalu E, D'Anna R, et al. (2002) Continental and subcontinental distributions of mtDNA control region types. Int J Legal Med 116: 99-108.

96. Vona G, Ghiani ME, Calo GM, Vacca L, Memmi M, et al. (2001) Mitochondrial DNA sequence analysis in Sicily. Am J Hum Biol 13: 576-589.

97. Di Rienzo A, Wilson AC (1991) Branching pattern in the evolutionary tree for human mitochondrial DNA. Proc Natl Acad Sci U S A 88: 1597-1601.
98. Ferri G, Ceccardi S, Lugaresi F, Bini C, Ingravallo F, et al. (2008) Male haplotypes and haplogroups differences between urban (Rimini) and rural area (Valmarecchia) in Romagna region (North Italy). Forensic Sci Int 175: 250-255.

99. Ferri G, Alu M, Corradini B, Radheshi E, Beduschi G (2009) Slow and fast evolving markers typing in Modena males (North Italy). Forensic Sci Int Genet 3: e31-33.

100. Contu D, Morelli L, Santoni F, Foster JW, Francalacci P, et al. (2008) Ychromosome based evidence for pre-neolithic origin of the genetically homogeneous but diverse Sardinian population: Inference for association scans. PLoS One 3: e1430. 